\title{
Prediction of Tensile Strength of Friction Stir Weld Joints with Adaptive Neuro-Fuzzy Inference System (ANFIS) and Neural Network
}

\author{
Mohammad W. Dewan' ${ }^{1}$, Daniel J. Huggett ${ }^{1}$, T. Warren Liao', Muhammad A. Wahab ${ }^{1 *}$, Ayman \\ M. Okeil ${ }^{2}$ \\ ${ }^{1}$ Department of Mechanical and Industrial Engineering, Louisiana State University, LA 70803, \\ USA \\ ${ }^{2}$ Department of Civil and Environmental Engineering, Louisiana State University, LA 70803, \\ USA \\ *Corresponding Author: wahab@me.lsu.edu \\ *Phone: +1-225-578-5823 / Fax: +1-225-578-5924
}

\begin{abstract}
Friction-stir-welding (FSW) is a solid-state joining process where joint properties are dependent on welding process parameters. In the current study three critical process parameters including spindle speed $(N)$, plunge force $\left(F_{z}\right)$, and welding speed $(V)$ are considered key factors in the determination of ultimate tensile strength (UTS) of welded aluminum alloy joints. A total of 73 weld schedules were welded and tensile properties were subsequently obtained experimentally. It is observed that all three process parameters have direct influence on UTS of the welded joints. Utilizing experimental data, an optimized adaptive neuro-fuzzy inference system (ANFIS) model has been developed to predict UTS of FSW joints. A total of 1200 models were developed by varying the number of membership functions (MFs), type of MFs, and combination of four input variables $\left(N, V, F_{z}, E F I\right)$ utilizing a MATLAB platform. Note EFI denotes an empirical force index derived from the three process parameters. For comparison, optimized artificial neural network (ANN) models were also developed to predict UTS from FSW process parameters. By comparing ANFIS and ANN predicted results, it was found that optimized ANFIS models provide better results than ANN. This newly developed best ANFIS model could be utilized for prediction of UTS of FSW joints.
\end{abstract}


Keywords: Friction stir welding; Welding process parameters; Tensile strength; Adaptive neurofuzzy inference system; Leave-one-out cross validation

\section{Introduction}

The main challenge for the friction-stir-welding (FSW) process is selecting welding parameters that would produce defect free and high strength joints. Since the development of the FSW process, trial and error techniques have been applied to find optimum weld parameters [1]. The quality of a FSW joint depends on several factors including tool design, clamp design, materials welded, and welding parameters. For a particular welding condition (i.e. pin tool, clamp, and material), the quality of a FSW joint depends on two factors: welding process parameters (i.e. spindle speed, welding speed, plunge depth / plunge force) and environmental factors (i.e. weld cooling, pre-weld cooling, weld location) [2]. Thus developing an appropriate physical model which can predict the process's main characteristics (weld defects and mechanical properties) is complex. Hence, researchers have attempted to build predictive models based on experimental data [3-8] and utilize nontraditional optimization algorithms such as the Taguchi method [9-12] and simulated annealing [13-15] to obtain optimum FSW process parameters. Other metaheuristic algorithms (i.e. ant colony optimization, differential evolution, particle swarm optimization, finite volume) have been used to determine optimal operating parameters for FSW processes [16]. In case of building data-driven empirical models as a part of the response surface methodology (RSM), a second order polynomial is often fitted $[3,5,8,17]$. However, the highly nonlinear behavior between FSW process parameters and tensile properties might not be well accommodated by the second order polynomial. Some investigators applied statistical learning models (i.e. Artificial Neural Network (ANN)) to predict mechanical responses of FSW joints [18-23]. Lakshminarayanan reported two articles on the comparison between RSM and ANN models to 
predict mechanical performances of FSW joints and concluded that the ANN model is much more robust and accurate in estimating tensile strength [22, 23]. Nevertheless, most of the abovementioned studies utilized limited experimental data and none are decisive.

Adaptive network-based fuzzy inference system (ANFIS) is a hybrid predictive model which make use of both neural network and fuzzy logic to generate mapping relationships between input and output [24]. Although ANFIS is a powerful modeling tool, there has been only one study [25] which has utilized said technique in modeling the FSW process. In that study, pin tool profile, spindle rotational speed, welding speed, and axial force were utilized as input variables to predict UTS, yield strength, and micro-hardness in FS welded 7075 aluminum alloy joints. The authors in [25] utilized 31 data sets to develop a predictive model and 10 data sets for testing. Building and testing models based on simple data splitting is known not to be reliable. For a small data set, the leave-one-out cross validation (LOO-CV) [26-29] technique is beneficial to train as many examples as possible.

The current investigation entails an experimental study with 73 weld schedules coupled with the development of an optimized ANFIS model to predict tensile properties of FSW joints of 2219-T87 aluminum alloy. The model employs the leave-one-out cross validation (LOO-CV) approach for the validation of prediction accuracy. For comparison, an optimized artificial neural network (ANN) model was also developed. The remainder of the paper is organized as follows. Section 2 introduces the modeling and validation methodologies used in the study. Section 3 describes the experiments and results. Sections 4 and 5 provide the ANFIS, ANN modeling, and validation results. The conclusions are given in the last section.

\section{Modeling and Validation Methods}




\subsection{Artificial Neural Network (ANN)}

The first artificial neural network (ANN) was invented in 1958 by psychologist Frank Rosenblatt called 'perceptron'. ANN is a computational model, which replicates the function of a biological network composed of neurons. ANN is often used to model complex nonlinear functions in various applications. The basic unit in the ANN is the neuron. Neurons are connected to each other by links known as synapses. Andersen et al. (1990) first applied ANN in the welding area to predict weld bead shape for the gas tungsten arc welding (GTAW) process [30]. Researchers have also applied ANN to develop predictive models for FSW joints [18-23]. A multilayer perceptron ANN system has three layers which are input, hidden, and output layers. The input layer consists of all the input factors. Information from input layer is then processed in the hidden layers, and then followed by the output layer (Figure 1). Details on the neural network modeling approach are given elsewhere [31].

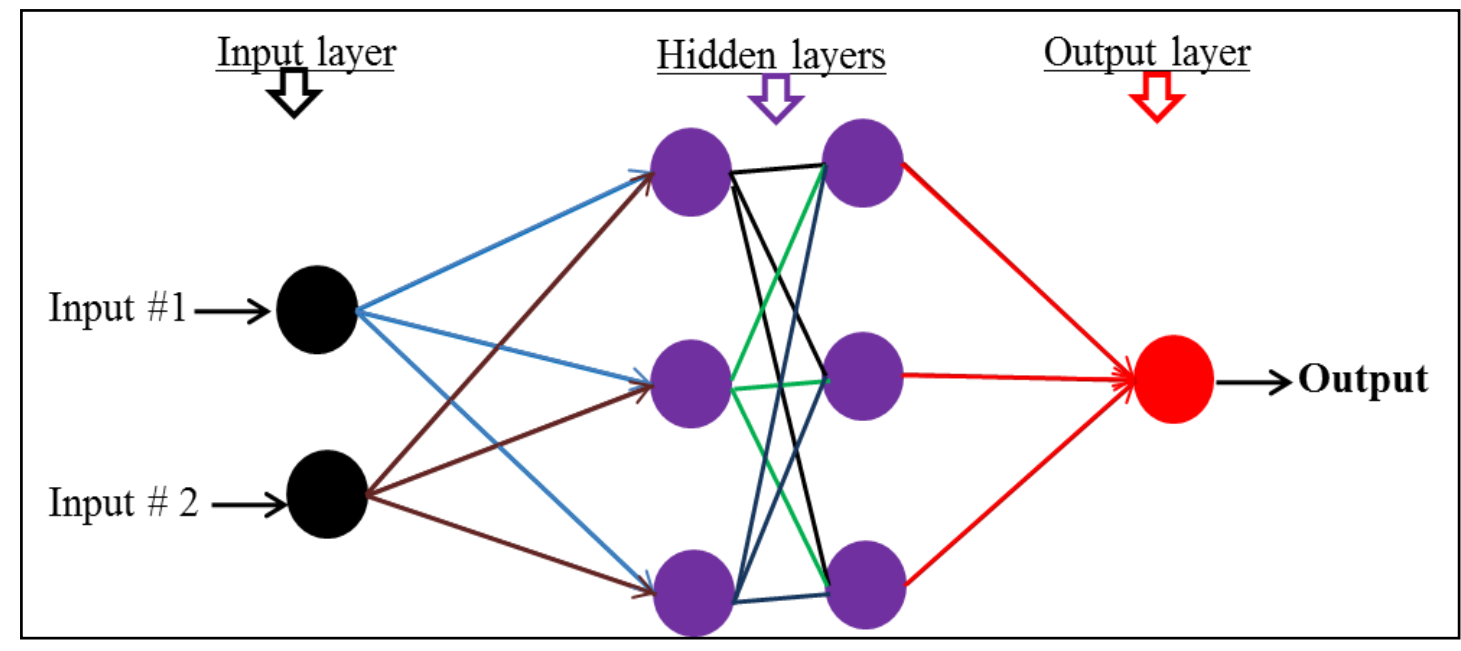

Figure 1: Schematic of artificial neural network (ANN) layers (two input variables, two hidden layers with 3 nodes each, and one output) 
Multilayer perceptron ANN can be learned using various algorithms; well-known learning algorithms include back-propagation, counter-propagation, and genetic algorithms. Backpropagation neural network has been usually used to model welding processes [32]; hence, it is adopted in this work. In building the model-input variables, training functions, and number of nodes in the hidden layer were varied to obtain a model that produces lowest root mean square error (RMSE) and mean absolute percentage error (MAPE). MATLAB (R2012a) platform was utilized to train and test the ANNs.

\subsection{Adaptive Neuro-Fuzzy Inference System (ANFIS)}

Adaptive Neuro-fuzzy Inference System (ANFIS) is a class of adaptive network framework proposed by Jang [24]. ANFIS constructs an input-output mapping based on human knowledge and generates input-output data pairs by using a hybrid algorithm. According to Jang, the ANFIS is a neural network that is functionally similar to the Takagi-Sugeno-Kang (TSK) type inference model [33]. The TSK rules can be described in equation (1).

$\operatorname{IF}\left(x_{1}=A_{i 1}^{1}\right)$ and $\left(x_{2}=A_{i 2}^{2}\right)$ and $\ldots$. and $\left(x_{n}=A_{i n}^{n}\right) \quad$ THEN $y=f\left(x_{j}\right)$

Where $x_{j}$ is the $j^{\text {th }}$ input $(j=1,2, \ldots \ldots, n), A_{i 1}^{1}$ is the $i^{t h}$ linguistic term defined as a fuzzy membership function on $x_{j}$, and the mapping function $f$ could be linear, nonlinear, or simply a real number [34]. Five distinct layers are used to explain the concept of the ANFIS structure [24]. The first layer is the fuzzification layer where crisp inputs are transformed into membership values by using the membership function at the node $i$. The output can be stated as equation (2).

$$
O_{i}^{1}=\mu_{x_{i}}(x)
$$

Where $\mu_{x i}$ is the $i^{t h}$ membership function for the input $x$. 
The second layer is the rule base layer. It calculates the firing strength for the next layer by multiplying linguistic inputs (assuming 2) to node $i$ of this layer (equation (3)).

$$
O_{i}^{2}=w_{i}=\mu_{x_{i}}(x) \times \mu_{y_{i}}(y)
$$

The third layer performs the normalization of membership values. The normalized firing strength at node $i$ of this layer is obtained using equation (4).

$$
O_{i}^{3}=\overline{w_{l}}=w_{i} / \sum_{j=1}^{K} w_{j} ; i=1,2,3 \ldots K
$$

$\mathrm{K}$ denotes number of nodes in this layer, with each corresponding to a unique rule.

The fourth layer is the adaptive layer. The relation between inputs (assuming 2, i.e., $\mathrm{x}$ and $\mathrm{y}$ ) and output can be defined as equation (5).

$$
O_{i}^{4}=\overline{w_{\iota}} \times p_{i}=\overline{w_{l}} \times\left(s_{i} x+f_{i} y+n_{i}\right)
$$

Where parameters $\mathrm{s}_{\mathrm{i}}, \mathrm{f}_{\mathrm{i}}$, and $\mathrm{n}_{\mathrm{i}}$ of node $i$ in this layer are called consequent parameters.

The fifth layer is the de-fuzzification layer and the output is the final result of all fuzzy rules. The results can be described as equation (6).

$$
O^{5}=\sum_{i=1}^{K} \overline{w_{l}} \times p_{i} ; i=1,2, \ldots K
$$

Where $p_{i}$ denotes the inferred output of the ANFIS rule $i$. Like neural network, in an ANFIS structure, the inputs of each layer are obtained from the nodes of the previous layer. Considering an ANFIS network with $n$ inputs $\left(x_{1} \ldots x_{n}\right)$ and each input having $m$ membership functions (MFs), the number of nodes $(N)$ in first layer is equal to the product of $n$ as number of inputs and $m$ as number of MFs $(N=m . n)$. The number of nodes in other layers (layer 2-4) relates to the number of fuzzy rules [24]. Figure 2 illustrates a typical ANFIS structure showing 5 different layers. 


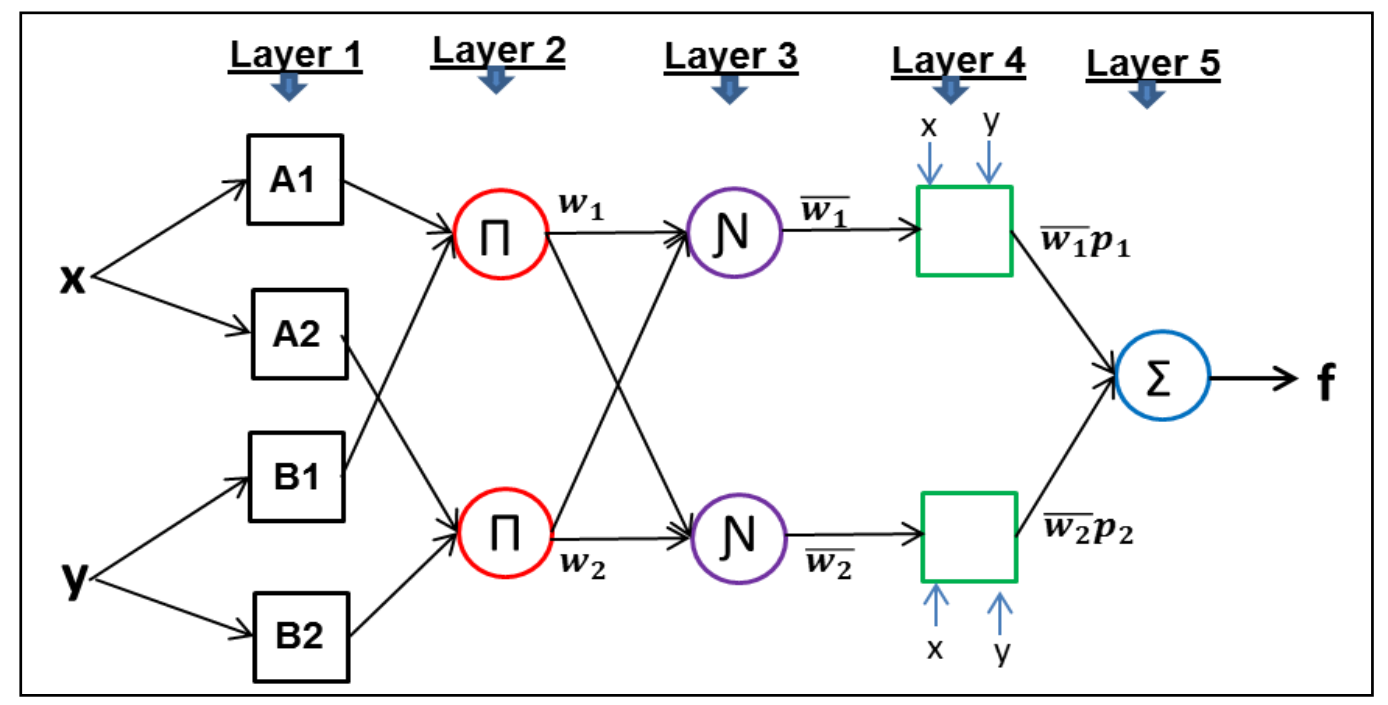

Figure 2: Schematic of ANFIS architecture for two inputs and two rules based on the first-order Sugeno model [24]

Construction of an ANFIS model requires the partition of the input-output data into rule patches. This can be achieved by using three different Generate Fuzzy Inference System (GENFIS) methods, i.e., grid partitioning, subtractive clustering method, and fuzzy c-means (FCM) [35]. In the Matlab FUZZY Toolbox, these are named GENFIS1, GENFIS2, and GENFIS3. GENFIS1 produces grid partitioning of the input space and GENFIS2 uses subtractive clustering to produce a scattering partition to define the membership functions. GENFIS3 uses fuzzy c-means (FCM) as a mechanism to cluster the inputs. Apart from structure identification, a fuzzy inference system has many other parameters that can be optimized, i.e., membership-function parameters and ruleconsequent parameters [35]. Success in obtaining a reliable and robust model depends heavily on the choice of the domain used for construction and training purposes. Important factors that contribute to produce an accurate ANFIS model include type of fuzzy based rule, number of MFs, and their function types. In this paper, a first order TSK type fuzzy-based rule is used for the creation of predictive models. Thereafter, different MF types (triangular, generalized bell, 
Gaussian, Gaussian combination) are applied to obtain the best model that produces minimum root mean square error (RMSE) and mean absolute percentage error (MAPE).

\subsection{Leave-One-Out Cross Validation (LOO-CV) Approach}

The leave-one-out cross-validation (LOO-CV) approach is a useful validation method for small data sets and has been applied for model selection [36]. In this technique, one sample is left out and the remaining samples are utilized to build a model. If $n$ numbers of samples are available in a given data set, each model is trained with $n-1$ samples and tested with the sample left out. This process is repeated $n$ times until every sample in the data set are utilized once as a crossvalidation instance. Finally, the RMSE and MAPE are calculated using equations 7 and 8 , respectively. The model with minimum RMSE and MAPE is then selected [26].

$$
\begin{aligned}
\text { RMSE } & =\sqrt{\frac{1}{n} \sum_{i=1}^{n}\left(e_{i}-a_{i}\right)^{2}} \\
\text { MAPE } & =\frac{1}{\mathrm{n}} \sum_{i=1}^{n}\left(\left|e_{i}-a_{i}\right|\right) / e_{i}
\end{aligned}
$$

Where, $n$ total number of samples, $e_{i}$ is experimental output, and $a_{i}$ is ANFIS model predicted output.

\section{Experiments and Results}

\subsection{Experiments}

FSW can be conducted in two control settings: position and load control. In position control, plunge depth is controlled along with spindle speed and welding speed. Whereas in load control, plunge force is controlled along with spindle speed and welding speed. In the current investigation, FSW was performed employing load control. A total of 73 weld schedules with different combinations of three FSW critical process parameters (rotational speed, welding speed, and plunge force) were conducted. Welding experiments were carried out on I-Stir PDS and UWS 
FS welders at the Michoud Assembly Facility (MAF) in New Orleans, Louisiana. A photograph of the PDS FS welder FSW setup with pin tool dimensions are illustrated in Figure 3. The experimental setup includes a fixture, pin tool, and welding material that remain constant through the entirety of the work. The fixture utilized for welding entailed a steel anvil. Steel bars (often called as "chill bars") were placed on the Advancing Side (AS) and Retreating Side (RS) of the panels and were used for clamping down the panels. The tool utilized is a two-piece fixed pin tool. The shoulder, made from $\mathrm{H} 13$ steel, has a scrolled shoulder of $30.48 \mathrm{~mm}$ diameter with $0.76 \mathrm{~mm}$ deep counter clockwise (CCW) spiral scroll of $2.92 \mathrm{~mm}$ pitch. The pin, which is interchangeable, is a $10^{\circ}$ tapered cone of MP159 Nickel-Cobalt based multiphase alloy, $10.16 \mathrm{~mm}$ average diameter at the shoulder and extending to a depth of $7.112 \mathrm{~mm}$. The material is $8.13 \mathrm{~mm}$ thick AA2219$\mathrm{T} 87(6.7 \% \mathrm{Cu}, 0.01 \% \mathrm{Mg}, 0.27 \% \mathrm{Mn}, 0.13 \% \mathrm{Fe}, 0.01 \% \mathrm{Si}, 0.12 \% \mathrm{Zr}, 0.05 \% \mathrm{Ti}$, balance $\mathrm{Al}$ in weight percent). Each panel comprised of two plates $152 \mathrm{~mm}$ wide and $609 \mathrm{~mm}$ long and joined together along the center line by a conventional butt-joint. To save material, two schedules were experimented on each panel. A weld schedule entails three process variables including plunge force, welding speed, and spindle rotational speed. The ranges of parameters are: rotational speed (N) $200 \mathrm{rpm}$ to $450 \mathrm{rpm}$, welding speed $(V) 76.2 \mathrm{~mm} / \mathrm{min}$ to $266.7 \mathrm{~mm} / \mathrm{min}$, and plunge force $\left(F_{z}\right)$ $12.46 \mathrm{kN}$ to $37.83 \mathrm{kN}$. 

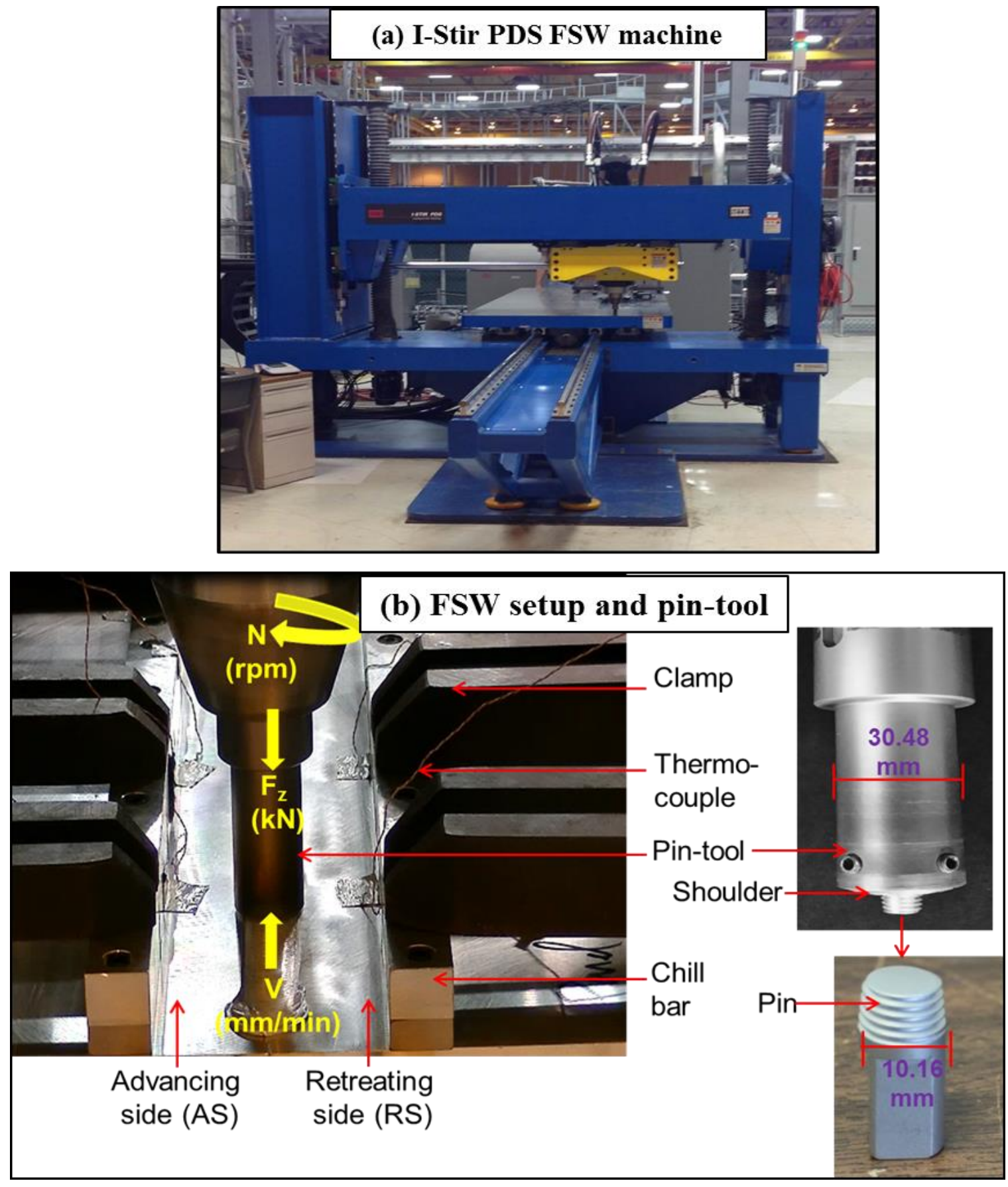

Figure 3: Photograph of (a) PDS FS welder and (b) FSW setup showing three critical process parameters $\left(F_{Z}, V, N\right)$ with pin-tool dimensions 
After welding, the crown surfaces of each panel were ground. Specimens were thereafter prepared for tensile tests. Three tensile specimens for each weld schedule were cut according to AWS specification for FSW of aluminum alloys [37] and tested according to ASTM E8/8M-11 at $1.0 \mathrm{~mm} / \mathrm{min}$ cross head speed. Dog-bone tensile test specimens before and after tensile tests are shown in Figure 4(a,b). During the tensile testing an extensometer was attached at the center of the specimens to acquire engineering strain values (Figure 4c).
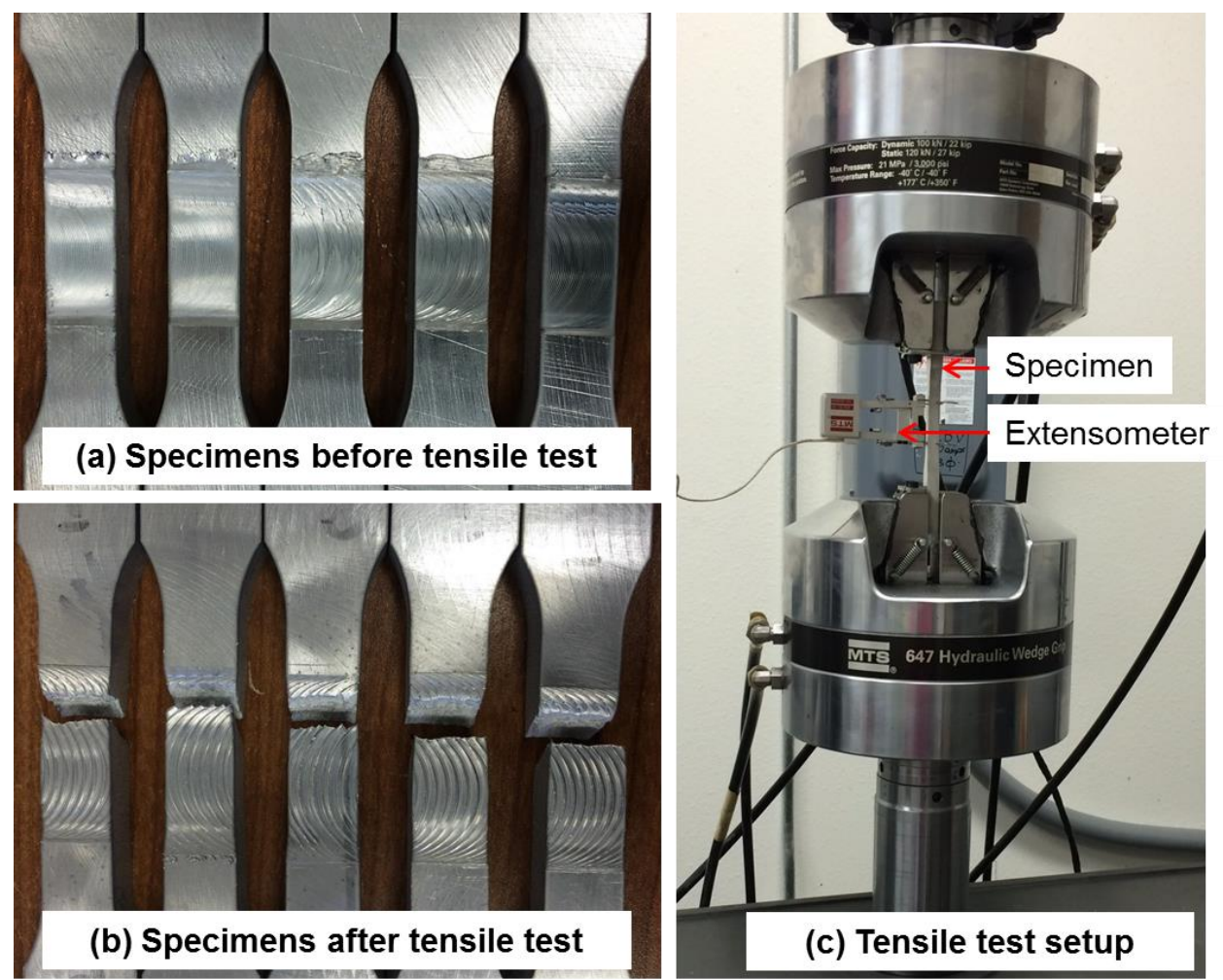

Figure 4: Photograph of tensile test specimens before test (a), specimens after test (b), and setup with extensometer (c)

\subsection{Experimental results}

For a particular pin tool and clamping condition, the quality of a weld largely depends on three critical process parameters, i.e. spindle speed $(N)$, welding speed $(V)$, and plunge force $\left(F_{z}\right)$. 
All three critical process parameters determine the heat input $[38,39]$. Usually high spindle speed results in high heat generation, while high welding speed results in low heat generation. Moreover, high plunge force is responsible for large heat generation and vice-versa. A window exists where adequate welding temperatures produce defect-free FSW joints. Excessive high temperatures promote voids and underfill and corresponding schedule is defined as a 'hot weld'. Inadequate temperatures promote Wormholes (WH) or internal cavities, Trenching (TR) or surface cavities, and Incomplete Penetration (IP) and are considered 'cold welds'. Three categories of weld quality are distinguished based on weld process parameters and anticipated weld defects. They are (i) hot weld (high spindle speed, low weld speed, and high plunge force), (ii) cold weld (low spindle speed, high weld speed, and low plunge force), and (iii) nominal weld (optimum spindle speed, welding speed, and plunge force). Stress-strain curves for base metal, nominal, hot, and cold welds are shown in Figure 5.

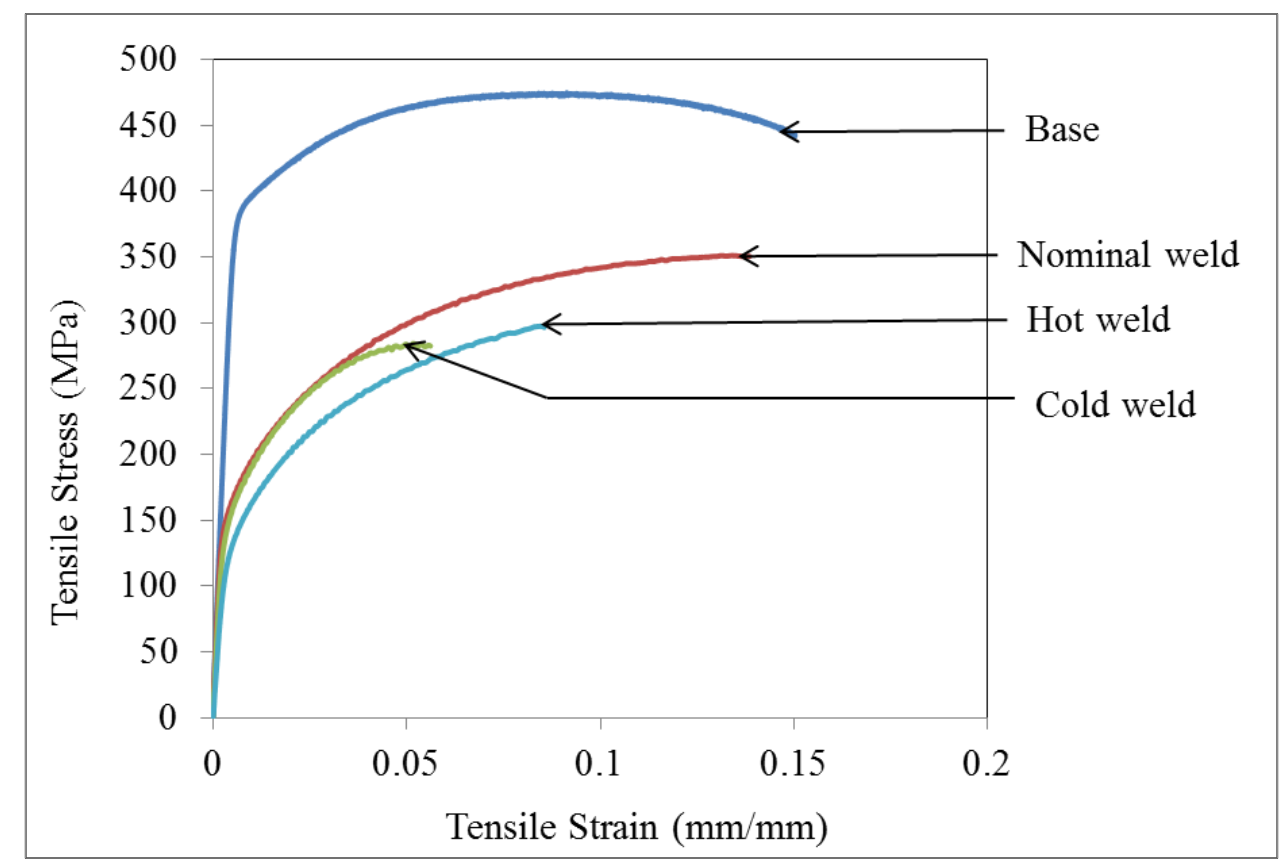

Figure 5: Stress-strain plots of base and FS welded AA2219-T87 specimens (base, nominal, hot, and cold welds) 
Nominal welds exhibited UTS and toughness values equal or more than $66 \%$ and $45 \%$ of base metal values. The variation in tensile strength and toughness values of nominal, hot, and cold welds are related to weld defects and microstructure. Typical weld nugget (WN) microstructures of nominal, hot, and cold welds are shown in Figure 6. The grain growth in weld nugget (WN) zone is related to heat input during the welding process [40]. The weld nugget of a defect free FSW joint is commonly composed of fine equiaxed grains (Figure 6a). The high heat input in hot weld has resulted in growth of dynamically recrystallized grain in weld nugget zone (Figure 6b). Alternatively, low heat input in cold welds hinder formation of fully dynamically recrystallized equiaxed grain (Figure 6c). The presence of weld defects and variations in microstructures are related to lower tensile properties of cold and hot welds joints.
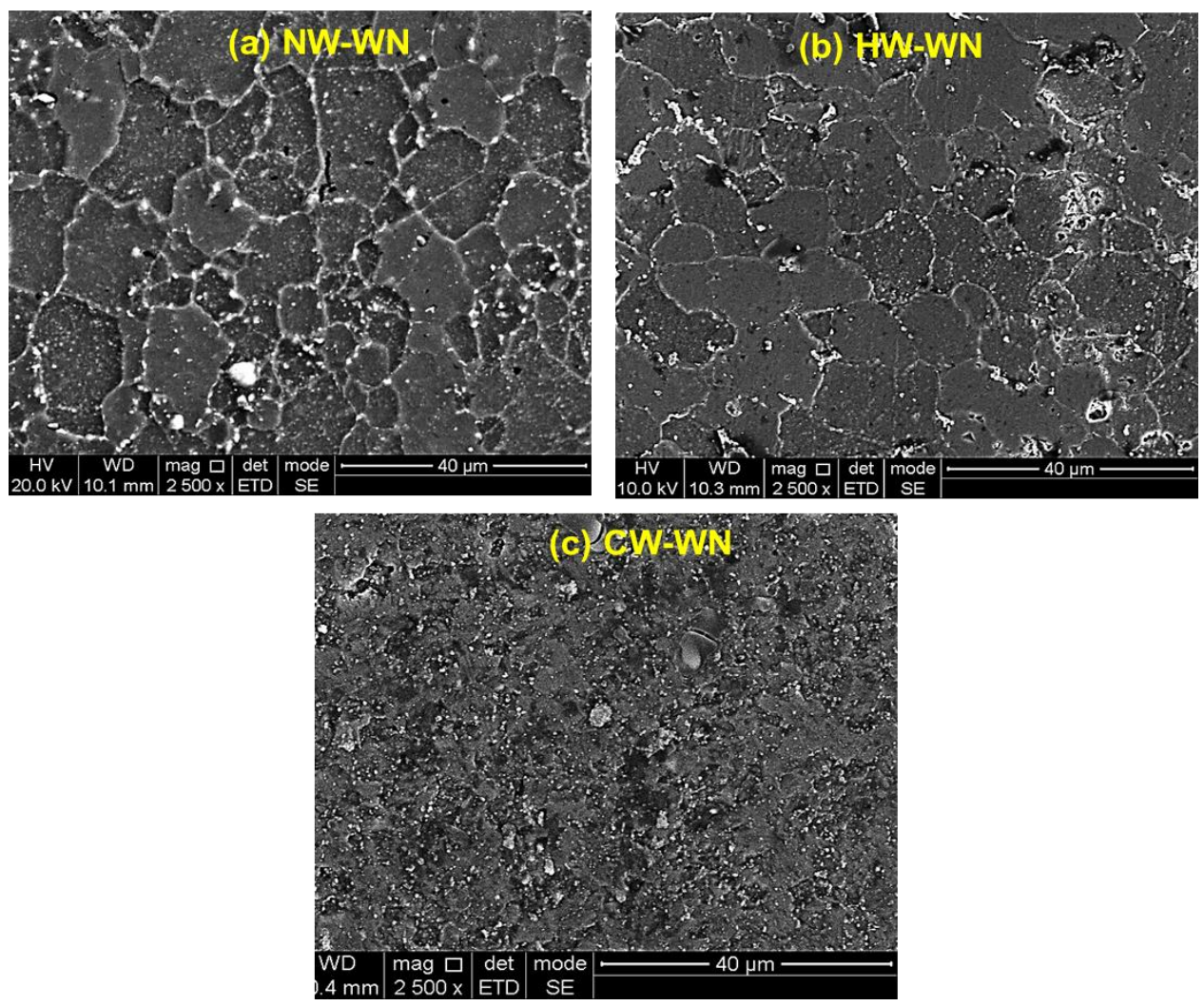

Figure 6: Typical SEM micrographs showing microstructure in weld nugget (WN) of (a) nominal weld (NW), (b) hot weld (HW), and (c) cold weld (CW) joints 
Figure 7 illustrates variation of UTS and toughness values with defect type. Nominal welds were observed to have highest average UTS (332 MPa) and toughness (37 MJ/m³), followed by HWs with UF and micro-voids (311 MPa and $\left.24 \mathrm{MJ} / \mathrm{m}^{3}\right)$, CW with IP (271 MPa and $15 \mathrm{MJ} / \mathrm{m}^{3}$ ), CW with WH (273 MPa and $\left.10 \mathrm{MJ} / \mathrm{m}^{3}\right)$, and CW with TR (170 MPa and $\left.5 \mathrm{MJ} / \mathrm{m}^{3}\right)$. Average UTS with weld process parameters are listed in Table 1.

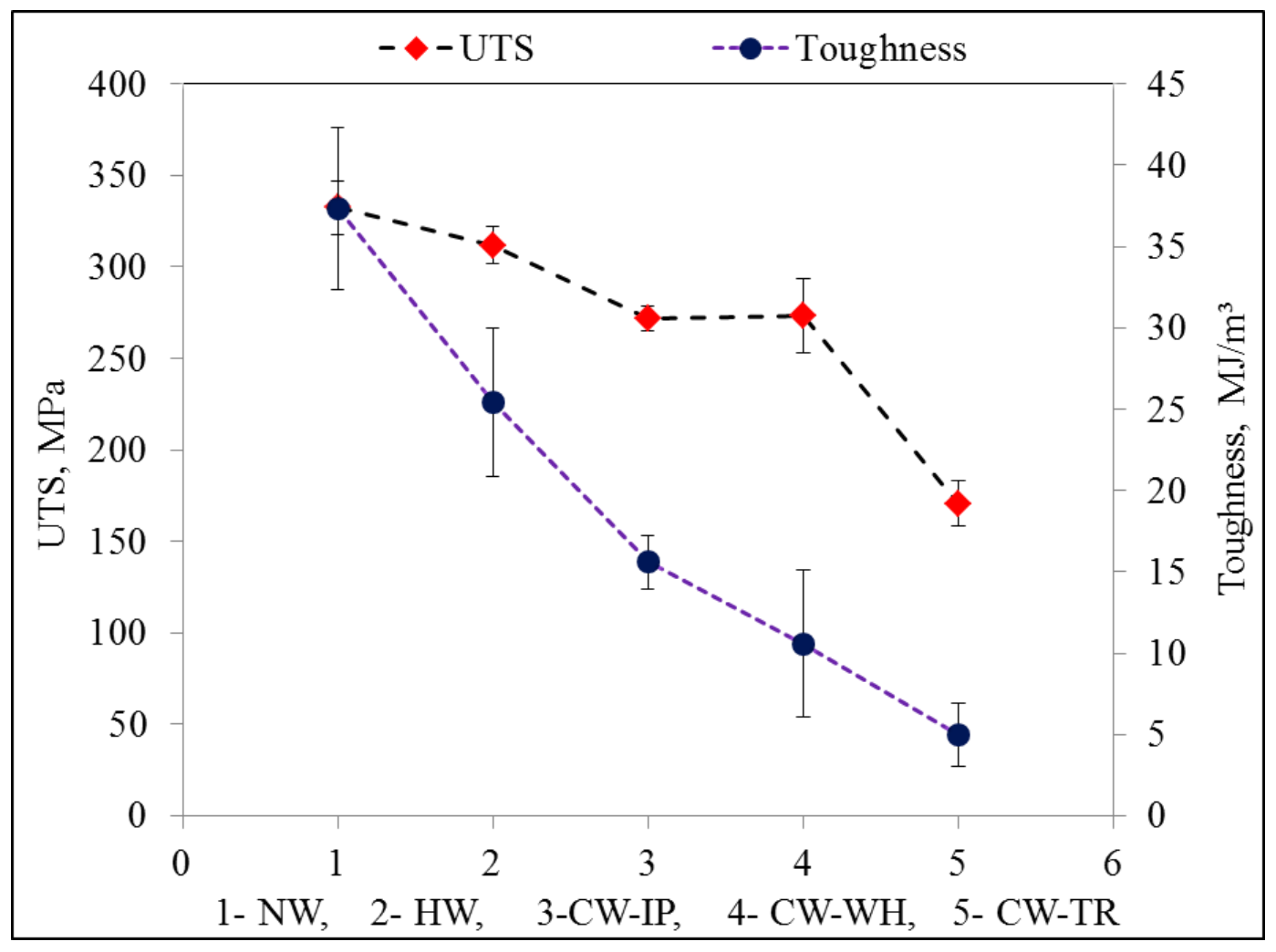

Figure 7: Ultimate tensile stregnth (UTS) and tensile toughness of FSW joint with different weld defects (NW: defect free nominal weld, HW: hot weld with underfill and micro-voids, CW-IP: cold weld with incomplete penetration, CW-WH: cold weld with wormhole, CW-TR: cold weld with trenching) 
Table 1: Friction stir welding process parameters and ultimate tensile strengths of AA-2219-T87 joints

\begin{tabular}{|c|c|c|c|c|c|c|c|c|c|c|c|}
\hline $\begin{array}{c}\text { SL } \\
\#\end{array}$ & $\begin{array}{c}\mathrm{N} \\
(\mathbf{r p m})\end{array}$ & $\begin{array}{c}\mathrm{V} \\
(\mathrm{mm} / \mathrm{min})\end{array}$ & $\begin{array}{c}\mathbf{F}_{\mathbf{z}} \\
(\mathbf{k N})\end{array}$ & $\begin{array}{l}\text { EFI } \\
(\mathbf{k N})\end{array}$ & $\begin{array}{c}\text { UTS } \\
\text { (MPa) }\end{array}$ & $\begin{array}{c}\mathbf{S L} \\
\#\end{array}$ & $\begin{array}{c}\mathrm{N} \\
(\mathbf{r p m})\end{array}$ & $\begin{array}{c}\mathrm{V} \\
(\mathrm{mm} / \mathrm{min})\end{array}$ & $\begin{array}{c}\mathbf{F}_{\mathbf{z}} \\
(\mathbf{k N})\end{array}$ & $\begin{array}{l}\text { EFI } \\
(\mathbf{k N})\end{array}$ & $\begin{array}{c}\text { UTS } \\
\text { (MPa) }\end{array}$ \\
\hline 1 & 300 & 152.40 & 21.13 & 0.84 & 288.12 & 38 & 350 & 76.20 & 16.68 & 1.07 & 324.41 \\
\hline 2 & 300 & 152.40 & 24.47 & 0.97 & 310.24 & 39 & 300 & 76.20 & 14.23 & 0.83 & 176.95 \\
\hline 3 & 350 & 152.40 & 17.79 & 0.77 & 172.95 & 40 & 300 & 152.40 & 27.58 & 1.10 & 317.33 \\
\hline 4 & 350 & 152.40 & 15.57 & 0.67 & 166.63 & 41 & 350 & 76.20 & 14.01 & 0.89 & 314.08 \\
\hline 5 & 200 & 152.40 & 26.69 & 0.84 & 283.38 & 42 & 350 & 76.20 & 17.79 & 1.14 & 314.44 \\
\hline 6 & 200 & 152.40 & 33.36 & 1.06 & 323.31 & 43 & 300 & 130.56 & 24.47 & 1.06 & 333.74 \\
\hline 7 & 450 & 152.40 & 33.36 & 1.66 & 260.17 & 44 & 350 & 152.40 & 26.69 & 1.16 & 314.44 \\
\hline 8 & 450 & 152.40 & 28.91 & 1.44 & 290.59 & 45 & 350 & 88.90 & 20.02 & 1.17 & 315.53 \\
\hline 9 & 450 & 152.40 & 35.59 & 1.77 & 211.72 & 46 & 300 & 101.60 & 22.24 & 1.11 & 335.62 \\
\hline 10 & 300 & 203.20 & 21.13 & 0.71 & 178.06 & 47 & 300 & 101.60 & 17.79 & 0.89 & 192.24 \\
\hline 11 & 300 & 203.20 & 24.47 & 0.83 & 279.81 & 48 & 200 & 135.38 & 26.69 & 0.90 & 267.32 \\
\hline 12 & 350 & 76.20 & 15.57 & 0.99 & 331.68 & 49 & 200 & 152.40 & 30.25 & 0.96 & 272.57 \\
\hline 13 & 350 & 152.40 & 20.02 & 0.87 & 353.98 & 50 & 300 & 76.20 & 17.79 & 1.04 & 320.65 \\
\hline 14 & 300 & 152.40 & 22.24 & 0.88 & 339.66 & 51 & 400 & 101.60 & 17.79 & 1.04 & 337.37 \\
\hline 15 & 300 & 152.40 & 20.02 & 0.79 & 279.06 & 52 & 400 & 77.98 & 15.57 & 1.06 & 327.46 \\
\hline 16 & 300 & 203.20 & 22.24 & 0.75 & 315.00 & 53 & 200 & 203.20 & 33.36 & 0.90 & 268.33 \\
\hline 17 & 300 & 203.20 & 20.02 & 0.68 & 237.74 & 54 & 350 & 88.90 & 17.79 & 1.04 & 343.43 \\
\hline 18 & 350 & 266.70 & 30.25 & 0.96 & 356.36 & 55 & 350 & 152.40 & 22.24 & 0.96 & 352.29 \\
\hline 19 & 350 & 236.98 & 26.69 & 0.90 & 359.96 & 56 & 350 & 152.40 & 20.02 & 0.87 & 349.41 \\
\hline 20 & 350 & 118.62 & 20.02 & 1.00 & 347.61 & 57 & 250 & 170.18 & 26.69 & 0.90 & 293.75 \\
\hline 21 & 350 & 88.90 & 16.46 & 0.96 & 333.45 & 58 & 200 & 152.40 & 36.48 & 1.15 & 326.49 \\
\hline 22 & 300 & 228.60 & 30.25 & 0.96 & 326.33 & 59 & 400 & 76.20 & 15.57 & 1.07 & 340.99 \\
\hline 23 & 200 & 152.40 & 31.14 & 0.98 & 313.99 & 60 & 350 & 152.40 & 24.47 & 1.06 & 336.01 \\
\hline 24 & 300 & 203.20 & 26.69 & 0.90 & 318.59 & 61 & 400 & 76.20 & 14.68 & 1.01 & 317.90 \\
\hline 25 & 200 & 152.40 & 27.58 & 0.87 & 267.75 & 62 & 300 & 76.20 & 22.24 & 1.30 & 322.09 \\
\hline 26 & 225 & 152.40 & 37.81 & 1.28 & 320.40 & 63 & 400 & 76.20 & 13.34 & 0.92 & 330.69 \\
\hline 27 & 300 & 152.40 & 33.36 & 1.32 & 292.16 & 64 & 250 & 76.20 & 23.58 & 1.25 & 315.43 \\
\hline 28 & 350 & 152.40 & 28.91 & 1.25 & 317.89 & 65 & 250 & 76.20 & 20.91 & 1.11 & 311.93 \\
\hline 29 & 300 & 101.60 & 16.01 & 0.80 & 167.38 & 66 & 300 & 203.20 & 31.14 & 1.05 & 343.12 \\
\hline 30 & 300 & 101.60 & 24.47 & 1.22 & 309.77 & 67 & 300 & 203.20 & 33.36 & 1.13 & 347.34 \\
\hline 31 & 350 & 88.90 & 15.57 & 0.91 & 326.84 & 68 & 300 & 228.60 & 33.36 & 1.06 & 346.34 \\
\hline
\end{tabular}




\begin{tabular}{|c|c|c|c|c|c|c|c|c|c|c|c|}
\hline 32 & 350 & 88.90 & 22.24 & 1.30 & 306.69 & 69 & 300 & 228.60 & 35.59 & 1.13 & 335.09 \\
\hline 33 & 350 & 76.20 & 12.46 & 0.80 & 157.56 & 70 & 300 & 228.60 & 31.14 & 0.98 & 354.05 \\
\hline 34 & 350 & 76.20 & 21.35 & 1.36 & 295.15 & 71 & 400 & 228.60 & 33.36 & 1.24 & 341.18 \\
\hline 35 & 300 & 152.40 & 21.69 & 0.86 & 335.87 & 72 & 400 & 228.60 & 24.47 & 0.91 & 347.44 \\
\hline 36 & 300 & 152.40 & 27.80 & 1.10 & 324.27 & 73 & 400 & 228.60 & 26.69 & 0.99 & 353.71 \\
\hline 37 & 350 & 76.20 & 14.46 & 0.92 & 320.25 & & & & & & \\
\hline
\end{tabular}

\section{ANFIS Modeling and Validation}

\subsection{Input variables for ANFIS model}

To obtain an optimized ANFIS model, a total of four input variables were utilized. The initial study began with only the three critical process parameters $\left(N, V\right.$, and $\left.F_{z}\right)$ as input variables. Thereafter, another input variable (i.e. empirical force index) is introduced to build a better ANFIS model. The empirical force index $(E F I)$ is derived from the three critical process parameters $\left(N, V\right.$ and $\left.F_{z}\right)$, as discussed below.

In a FSW process, the spindle speed $(N)$ and welding speed $(V)$ has opposite consequences on the frictional heat generation [41]. It is believed that a better way to represent welding process parameters in a more concise manner can be achieved by combining $N$ and $V$ together [42] for the purpose of creating a 2-D plot to represent weld schedules. A dimensionless speed ratio (R) has been proposed as a function of $N$ and $V$ for correlating with plunge force $\left(F_{Z}\right)$. To obtain a dimensionless speed ratio, $N$ was multiplied with the circumference of the pin-tool $(2 \pi r)$ and divided with $\mathrm{V}$. After multiplying $\mathrm{N}$ with $(2 \pi r)$, a unit similar to welding speed is obtained (i.e. $\mathrm{mm} / \mathrm{min}$ ). The dimensionless speed ratio $(R)$ is expressed in equation (9). Here, $\mathrm{r}$ is the pin tool radius.

$$
R=\frac{2 \pi r N}{V}
$$


The effect of individual process parameters on UTS is shown in Figure 8. Figure 8a plots speed ratio vs. UTS for two particular plunge forces, i.e. $22.25 \mathrm{kN}$ and $26.69 \mathrm{kN}$ whereas Figure $8 \mathrm{~b}$ plots plunge force vs. UTS for two different speed ratios (73.27 and 146.53). For a constant plunge force a narrow range of speed ratios exist where defect-free welds with high tensile properties are obtained. Furthermore, at a constant speed ratio a narrow range of plunge forces exists where maximum tensile properties are obtained. Away from the desirable window, low plunge force results in cold welds and high plunge force result in hot welds. As the plunge force increases, a lower speed ratio is required to obtain better tensile strength. Alternatively, as the speed ratio increases, a lower plunge force is required to obtain better tensile strength.
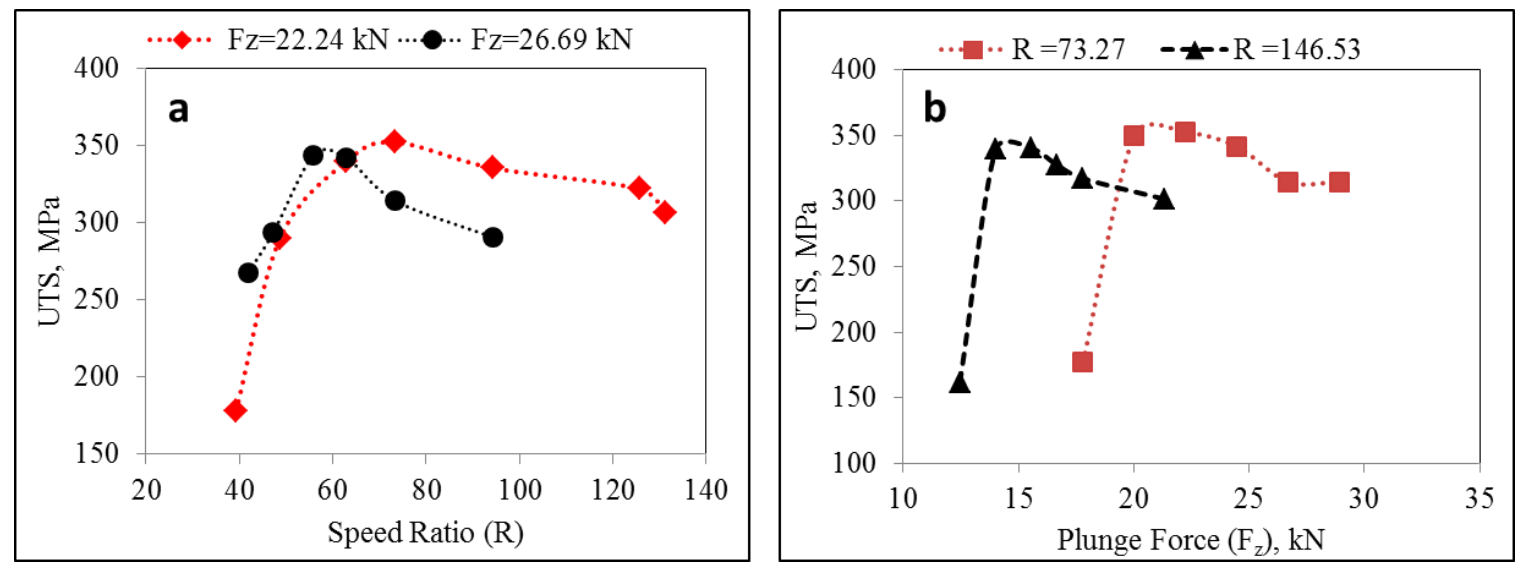

Figure 8: Effect speed ratio (R) on tensile strength: (a) Speed ratio vs. UTS at constant $F_{z}$, (b) $F_{z}$ vs. UTS at constant speed ratio

From Figure 8 , it is clear that all three critical process parameters $\left(N, V\right.$, and $\left.F_{z}\right)$ have direct effect on tensile strength. Consequently, the plunge force $\left(F_{z}\right)$ vs. speed ratio $(R)$ is plotted (Figure 9) to identify defective and defect free weld schedules. Any schedule within the bounded region produces defect-free nominal welds. Two lines have been superimposed to illustrate the (nominal/hot) and (nominal/cold) weld boundaries. Schedules above the bounded line contributes 
to hot welds and schedules below the bounded line produce cold welds. For nominal welds, the values of $F_{Z}$ vs. $R$ constitute a field and their relation in non-linear. It is also observed that as the speed ratio increases, a lower plunge force is required for achieving defect free nominal welds with higher UTS. Using a non-linear regression approach, a correlation between plunge force and speed ratio for producing defect free nominal welds can be written as equation (10).

$$
F_{z}=C_{1}(R)^{-C_{2}}
$$

Where, $F_{z}$ is the plunge force and $R$ is the dimensionless speed ratio. The Constant $C_{1}$ and the exponent $C_{2}$ depend on welding material, pin tool design, and other welding conditions (e.g., clamping condition, chill bar, backing plate, environmental temperature conditions, etc.). These constants $\mathrm{C}_{1}$ and $\mathrm{C}_{2}$ can be determined experimentally. In the current study, the values of $C_{1}$ and the exponent $C_{2}$ are 256.93 and 0.561 , respectively, fitted from defect-free nominal weld data. In other words, equation (10) has been found to be valid for defect-free nominal welds. Now, the EFI can be written as seen in equation (11), which is a dimensionless ratio. When this non-dimensional EFI value deviates from unity, defect free welding conditions are lost.

$$
E F I=\frac{F_{Z}}{C_{1}(R)^{-C_{2}}}
$$




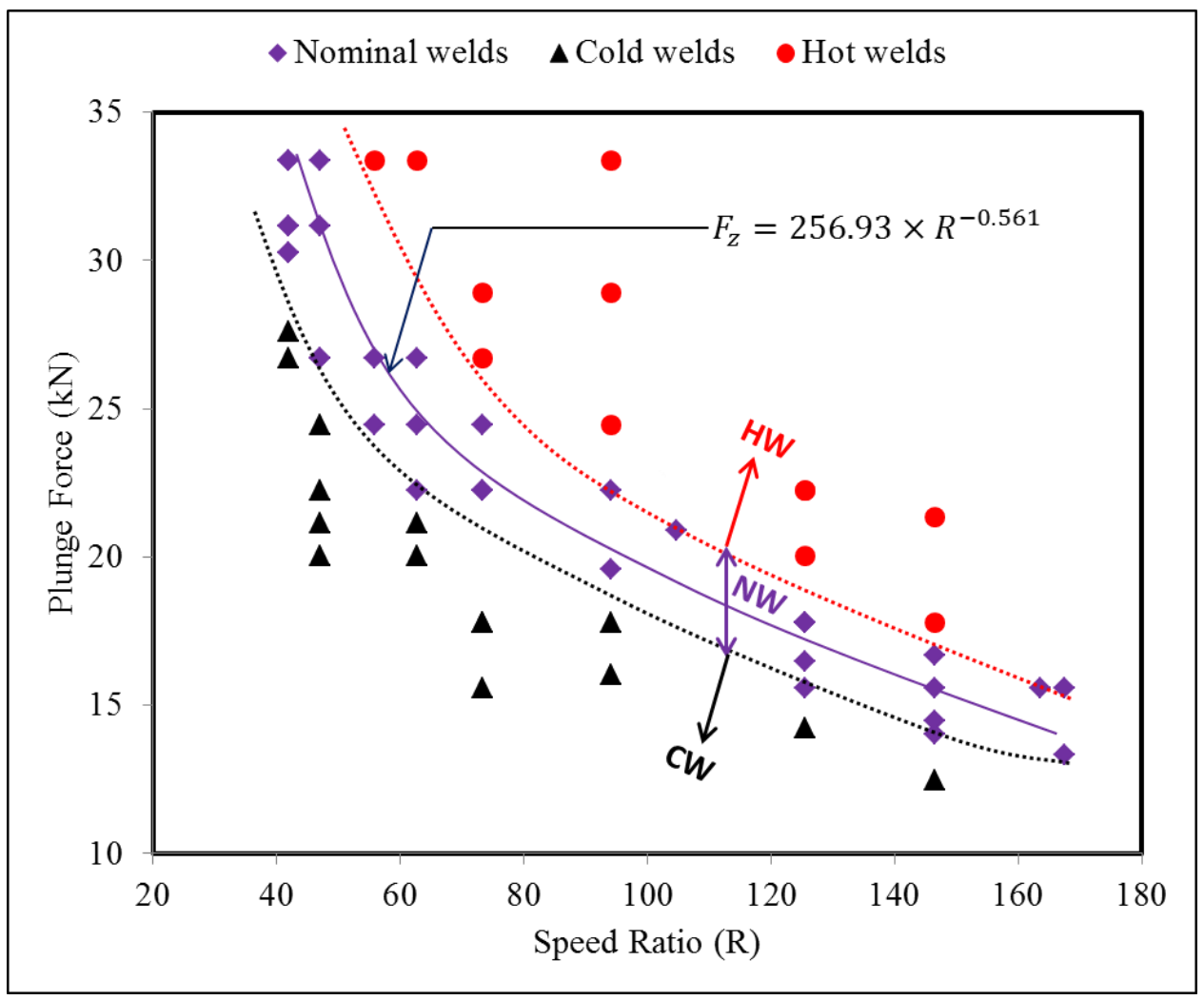

Figure 9: Welding process parameter window and correlation among three critical process parameters $\left(N, V, F_{z}\right)$ for defect free nominal weld schedules

The empirical force index vs. experimental UTS plot is shown in Figure 10, which indicates that for EFI values deviating from one, a drop in UTS occurs. The change in EFI from 1 on the left and right hand side of Figure 10 is related to the defects formed during welding. A range of EFI values exist where high UTS can be obtained. The non-linear behavior as well as uncertainty in process parameters and tensile strength makes it difficult to model the correlation between process parameters and UTS. This is the main reason why statistical learning modeling (i.e. ANFIS and ANN) has been employed to develop a predictive model. 


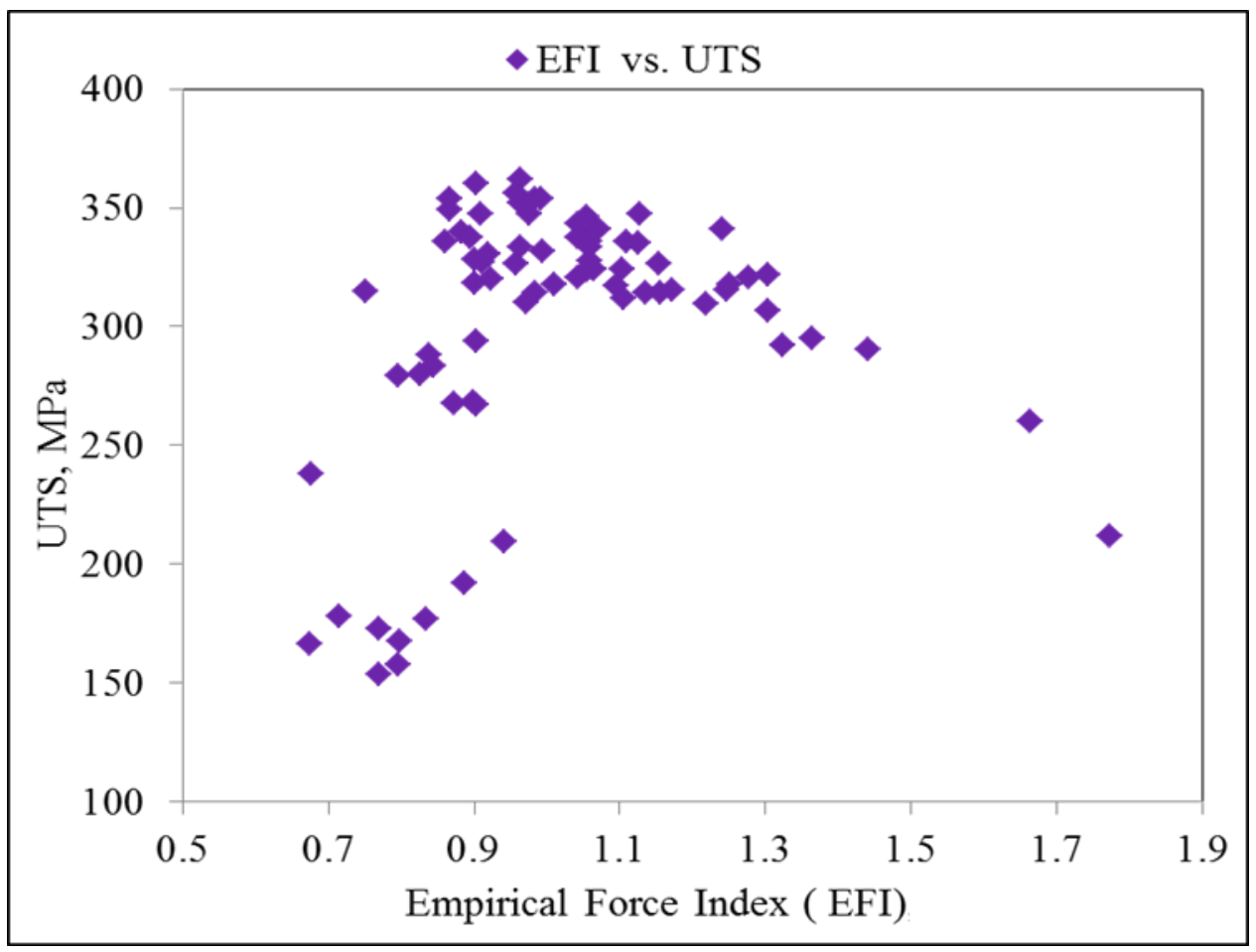

Figure 10: Experimental transverse ultimate tensile strength (UTS) of friction stir welded aluminum alloy joints are plotted against empirical force index (EFI)

\subsection{Building a better ANFIS model to predict tensile strength}

The experimental investigation indicates three critical process parameters $\left(N, V, F_{Z}\right)$ have direct influence on UTS of FSW joints. It is desirable to obtain a model that is able to accurately predict tensile strength for a given set of FSW process parameters. In this study an optimized adaptive neuro-fuzzy inference system (ANFIS) is developed to predict tensile strength as a function of four input variables $\left(N, V, F_{z}\right.$, and $\left.E F I\right)$ using experimental data listed in Table 1.

A preliminary study was first conducted using an exhaustive search technique to obtain a best input parameter set. Before the exhaustive search, all 73 data points were randomized and divided into 50 training instances and 23 testing data instances. The same procedure was repeated four times. Figure 11 indicates that for the same data set, different runs result in different results. 
The variation might be caused by randomization and the bias in dividing training and testing data. To avoid this issue, all possible combinations of four input variables were subsequently tested with the leave-one-out cross validation (LOO-CV) technique to develop the best ANFIS model. Details of developing the optimized ANFIS model are discussed below.
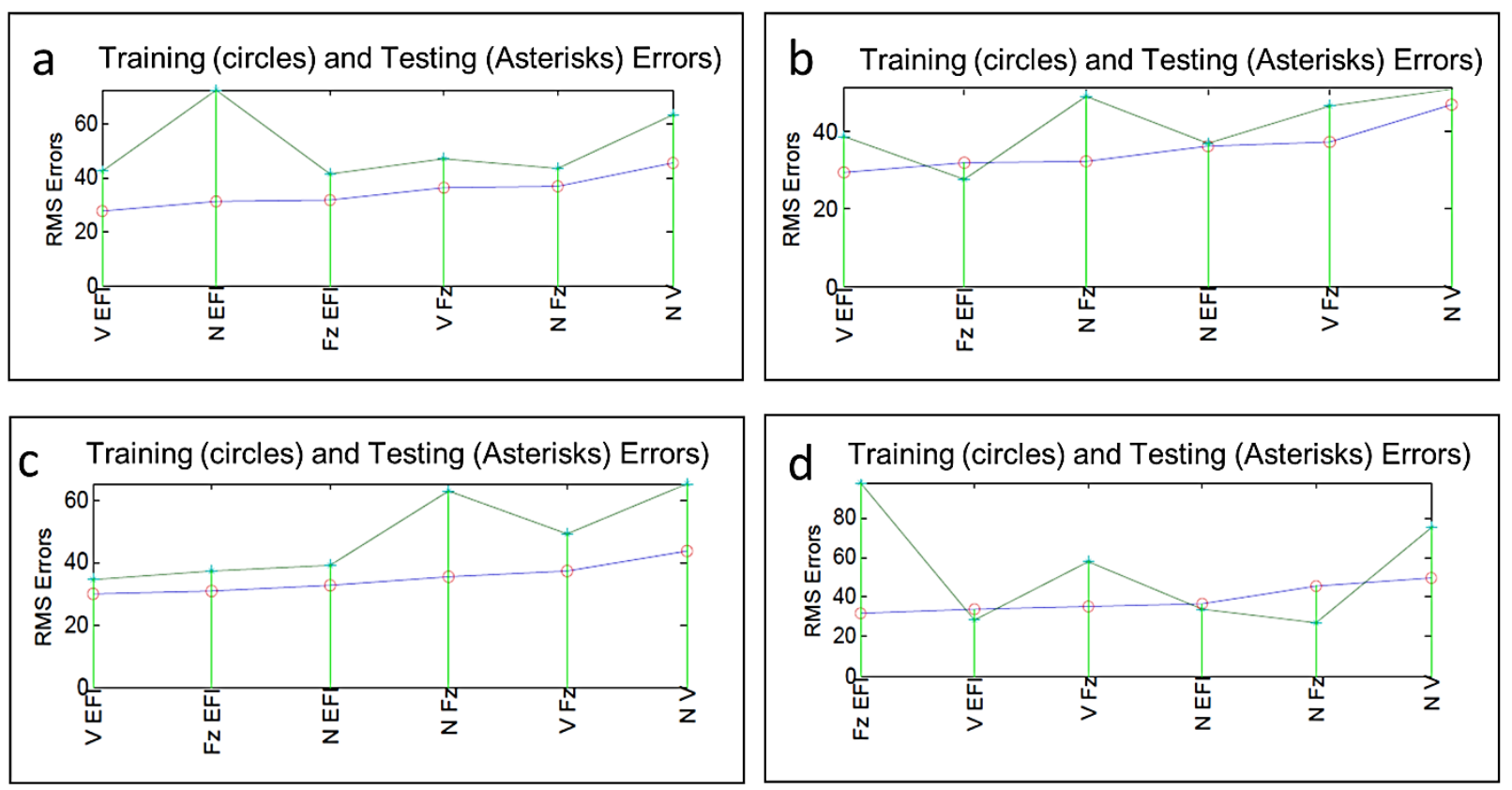

Figure 11: Variations of root mean square (RMS) error for different set of training and testing data

Initial modeling began with the three input variables: rotational speed $(N)$, welding speed $(V)$, and plunge force $\left(F_{z}\right)$. Utilizing grid partitioning fuzzy interference system (GENFIS1) with different combinations of three input variables $\left(\mathrm{N}, \mathrm{V}, \mathrm{F}_{\mathrm{z}}\right)$ and varied number and type of membership functions (MFs) a total of 280 models were developed. Each model was related to a particular membership function and number of membership function for each input variable. Number of membership functions was varied from ' 1 to 3 ' along with ' 5 ' different types of membership functions (i.e. trimf, gbellmf, gaussmf, gauss $2 \mathrm{mf}$, and pimf). In the ANFIS model, at 
least one of the input variable's 'number of membership functions (\# MFs)' should be greater than one. Therefore, the number of models can be defined as equation (12).

$$
\text { Number of Models }=\left[(n)^{i} \times m-m\right] \times c
$$

Where ' $n$ ' is the number of membership functions ( $n=3$ ), ' $i$ ' denotes total number of input variable utilized to build model, ' $\mathrm{m}$ ' is the different types of MFs $(\mathrm{m}=5)$, and ' $\mathrm{c}$ ' is the number of combination of input variables. For example, 3 individual input variables $\left([N]\right.$, or $[V]$, or $\left.\left[F_{z}\right]\right)$ result in $\left(3^{1} \times 5-5\right) \times 3=30$ models. Similarly, 3 different combinations of two input variables $\left([N, V]\right.$, or $\left[N, F_{z}\right]$, or $\left.\left[V, F_{z}\right]\right)$ result in $\left(3^{2} \times 5-5\right) \times 3=120$ models and 1 combination of three input variables $\left(\left[N, V, F_{z}\right]\right)$ result in $\left(3^{3} \times 5-5\right) \times 1=130$ models. Selected models with different combinations of input variables, types and numbers of membership functions associated with input variables are listed in Table 2. The ANFIS model with $(1,1,2)$ Gaussian membership functions for the three input variables $\left(N, V, F_{z}\right)$ produced the lowest RMSE (36.87 MPa) and MAPE (10.92 $\%)$ values.

Table 2: Result from ANFIS model developed utilizing different combinations of three input variables $\left(N, V, F_{z}\right)$ along with types and numbers of membership functions associated with input variables

\begin{tabular}{|c|c|c|c|c|c|}
\hline \multicolumn{3}{|c|}{ Number of 'mf' } & & & \\
\hline $\mathbf{N}$ & $\mathbf{V}$ & $\mathbf{F z}$ & Type of 'mf' & RMSE (MPa) & MAPE (\%) \\
\hline 3 & - & - & trimf & 50.74 & 14.70 \\
\hline - & 2 & - & pimf & 50.80 & 15.17 \\
\hline- & - & 2 & pimf & 51.60 & 15.99 \\
\hline 3 & 1 & & pimf & 50.40 & 14.65 \\
\hline - & 2 & 2 & gbellmf & 43.29 & 12.45 \\
\hline - & 1 & 3 & gaussmf & 45.56 & 13.67 \\
\hline 1 & 1 & 2 & gaussmf & 36.87 & 10.92 \\
\hline
\end{tabular}


Based on the LOO-CV technique a total of 73 data pairs of actual experimental outputs and ANFIS predicted outputs were obtained for each model. In Figure 12, the ANFIS predicted and experimental UTS values are plotted for best ANFIS model developed using three input variables. If the actual experimental and ANFIS predicted UTS values match perfectly, then all points should follow the diagonal line.

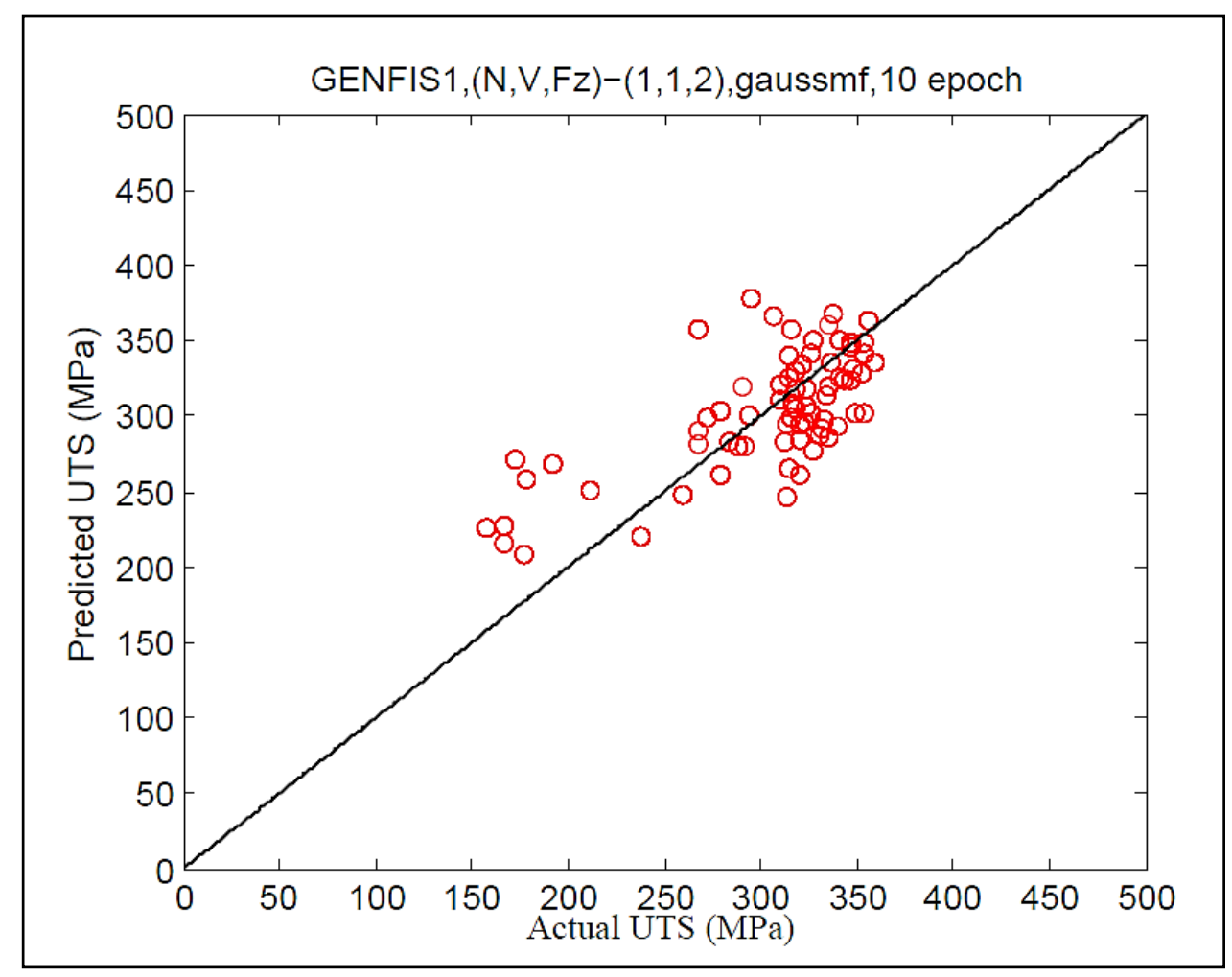

Figure 12: Experimental and ANFIS model predicted UTS plotted for best the model developed utilizing three input variables $\left(N, V, F_{z}\right)$

For further optimization, the empirical force index (EFI) was added as an input variable along with the three process parameters $\left(N, V, F_{z}\right)$. A total of 920 models were developed utilizing different combinations of the four input variables $\left(N, V, F_{z}, E F I\right)$ where EFI was reserved at every combination, along with varying number and type of membership functions. With different 
number and type of membership functions, using only individual input variable (EFI) result in a total of $\left(3^{1} \times 5-5\right) \times 3=10$ models. Similarly 3 different combinations of two input variables $([N$, $E F I]$, or $[V, E F I]$, or $\left.\left[F_{z}, E F I\right]\right)$ result in $\left(3^{2} \times 5-5\right) \times 3=120$ models, 3 different combination of three input variables $\left([N, V, E F I],\left[V, F_{z}, E F I\right],\left[V, F_{z}, E F I\right]\right)$ result in $\left(3^{3} \times 5-5\right) \times 3=390$ models, and 1 combination of four input variables $\left(\left[N, V, F_{z}, E F I\right]\right)$ result in $\left(3^{4} \times 5-5\right) \times 1=400$ models. As mentioned earlier, each model is related to a particular membership function (i.e. trimf, gbellmf, gaussmf, gauss $2 \mathrm{mf}$, pimf) and number of membership function (i.e. 1 to 3) for each input variable. Selected models with low RMSE and MAPE values are listed in Table 3. It is very interesting to observe that the ANFIS model developed utilizing only EFI as the input variable results in lower RMSE (36.51 MPa) and MAPE $(9.90 \%)$ values than the best model developed with 3 input variables without incorporating EFI (Table 2). In the current investigation, ANFIS models were developed based on first order TSK inference model. The highly nonlinear behavior between weld process parameters and UTS might result in higher RMSE and MAPE values in model developed without EFI. In EFI, weld process parameters are non-linearly related; this non-linear relation might be the reason for lower RMSE and MAPE values in ANFIS model developed utilizing EFI.

Nevertheless, EFI incorporated with other input variables was found to obtain the lowest RMSE and MAPE values. Specifically, the ANFIS model with $(2,1,3) \pi$-membership functions for $V, F_{z}$, and EFI produced the lowest RMSE (29.7 MPa) and MAPE (7.7\%) values. Similarly, the experimental and ANFIS model predicted UTS values are plotted in Figure 13. In Figure 13, a lesser amount of scattering is observed as compared to Figure 12. Lower scattering indicates a better model with lower RMSE and MAPE values; however, there are discrepancies observed between predicted and actual UTS data. The discrepancies might be related to the large variations 
in experimental UTS values produced by different weld schedules. Taking defect-free nominal welds as examples, UTS values vary from 310 to $360 \mathrm{MPa}$ with a standard deviation of $13 \mathrm{MPa}$.

Table 3: Result from ANFIS model developed utilizing four input variables $\left(N, V, F_{z}, E F I\right)$

\begin{tabular}{|c|c|c|c|c|c|c|}
\hline \multicolumn{4}{|c|}{ Number of 'mf' } & \multirow[b]{2}{*}{ Type of 'mf' } & \multirow[b]{2}{*}{ RMSE (MPa) } & \multirow[b]{2}{*}{ MAPE (\%) } \\
\hline $\mathrm{N}$ & $\mathrm{V}$ & $\mathrm{Fz}$ & EFI & & & \\
\hline & & & 3 & gaussmf & 36.51 & 9.90 \\
\hline 1 & & & 4 & gauss $2 \mathrm{mf}$ & 34.76 & 9.34 \\
\hline & 2 & & 3 & pimf & 30.84 & 8.28 \\
\hline & & 2 & 3 & pimf & 31.82 & 8.78 \\
\hline 1 & 2 & & 3 & pimf & 31.02 & 7.96 \\
\hline 1 & & 2 & 3 & pimf & 31.86 & 7.87 \\
\hline & 2 & 1 & 3 & pimf & 29.70 & 7.75 \\
\hline 1 & 1 & 2 & 3 & pimf & 30.68 & 7.81 \\
\hline
\end{tabular}

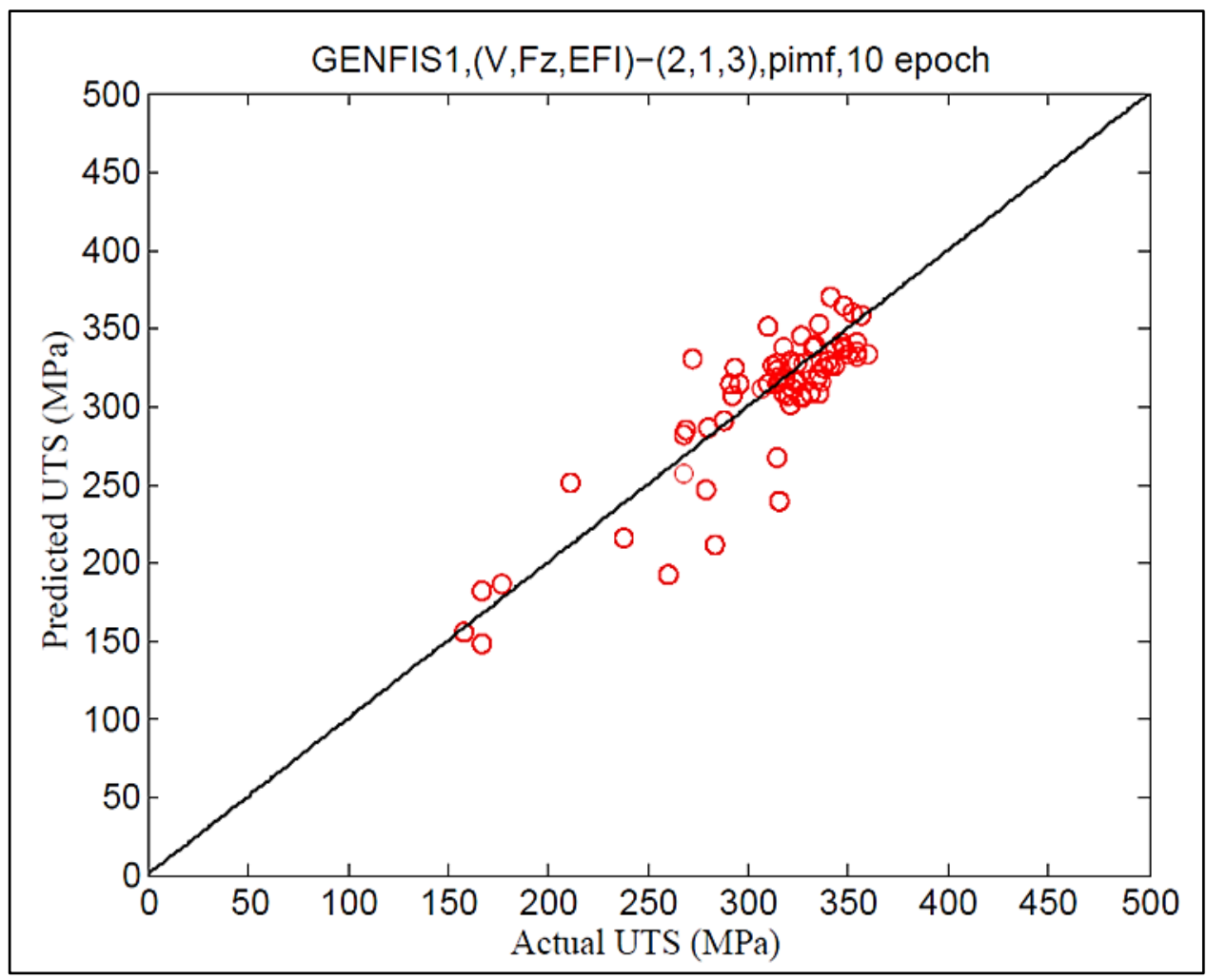

Figure 13: Experimental and ANFIS model predicted UTS plotted for best the model developed utilizing three input variables $\left(V, F_{z}, E F I\right)$ 
In previous sections, GENFIS1 structure was applied and optimized by varying combinations of input variables, number, and type of membership functions. As mentioned before, GENFIS1 produces grid partitioning of the input space. To investigate performances, the other two partitioning methods for generating initial fuzzy inference system, namely GENFIS2 and GENFIS3, were utilized for modeling (also available in the MATLAB fuzzy toolbox). For both GENFIS2 and GENFIS3, the leave-one-out cross-validation (LOO-CV) technique was also applied as in GENFIS1. Using the GENFIS2 structure, optimized ANFIS model was developed by varying two parameters, namely 'radii', 'epoch number', and number of input variables $\left(N, V, F_{z}\right.$, and $\left.E F I\right)$. The ANFIS model with $V, F_{z}$, and $E F I$ as input variables and 'radii $=0.5$ ' 'epoch=20' produces the lowest RMSE (38.40 MPa) and MAPE (10.06\%). In the case of GENFIS3, number of input variables, 'number of a clusters' and 'epoch number' were varied in the process to obtain the best ANFIS model. Using GENFIS3, the ANFIS model with $V, F_{z}$, and EFI as input variables and 'number of clusters=4' and 'epoch numbers $=20$ ' has the lowest RMSE (38.71 MPa) and MAPE (10.28\%). In summary, the ANFIS model generated with the GENFIS1 structure using three input variables $\left(V, F_{z}\right.$, and $\left.E F I\right)$ results in the lowest RMSE (29.7 MPa) and MAPE (7.7 \%) values.

For validation of the developed ANFIS model, 6 schedules were experimented having different spindle speed $(N)$, welding speed $(V)$, and plunge force $\left(F_{z}\right)$. Tensile strength for these tests were obtained and compared to the ANFIS model. Welding process parameters along with experimental and ANFIS predicted UTS are listed in Table 4. ANFIS predicted UTS values are comparable with the experimental data. The details of the best ANFIS model are given in Table 5.

Table 4: Comparison between experimental and ANFIS predicted UTS 


\begin{tabular}{ccccccc}
\hline Schedule & $\begin{array}{c}\mathrm{N} \\
(\mathrm{RPM})\end{array}$ & $\begin{array}{c}\mathrm{V} \\
(\mathrm{mm} / \mathrm{min})\end{array}$ & $\begin{array}{c}\text { Fz } \\
(\mathrm{kN})\end{array}$ & EFI & $\begin{array}{c}\text { Experimental } \\
\text { UTS (MPa) }\end{array}$ & $\begin{array}{c}\text { ANFIS predicted } \\
\text { UTS (MPa) }\end{array}$ \\
\hline 1 & 250 & 228.60 & 36.48 & 1.04 & 336.69 & 341.08 \\
2 & 250 & 228.60 & 40.03 & 1.14 & 346.47 & 344.09 \\
3 & 250 & 203.20 & 28.91 & 0.88 & 285.38 & 286.29 \\
4 & 400 & 203.20 & 20.91 & 0.83 & 314.92 & 317.86 \\
5 & 400 & 203.20 & 23.58 & 0.94 & 357.46 & 349.02 \\
6 & 400 & 203.20 & 26.69 & 1.06 & 348.17 & 340.16 \\
\hline
\end{tabular}

Table 5: ANFIS parameters for the best model

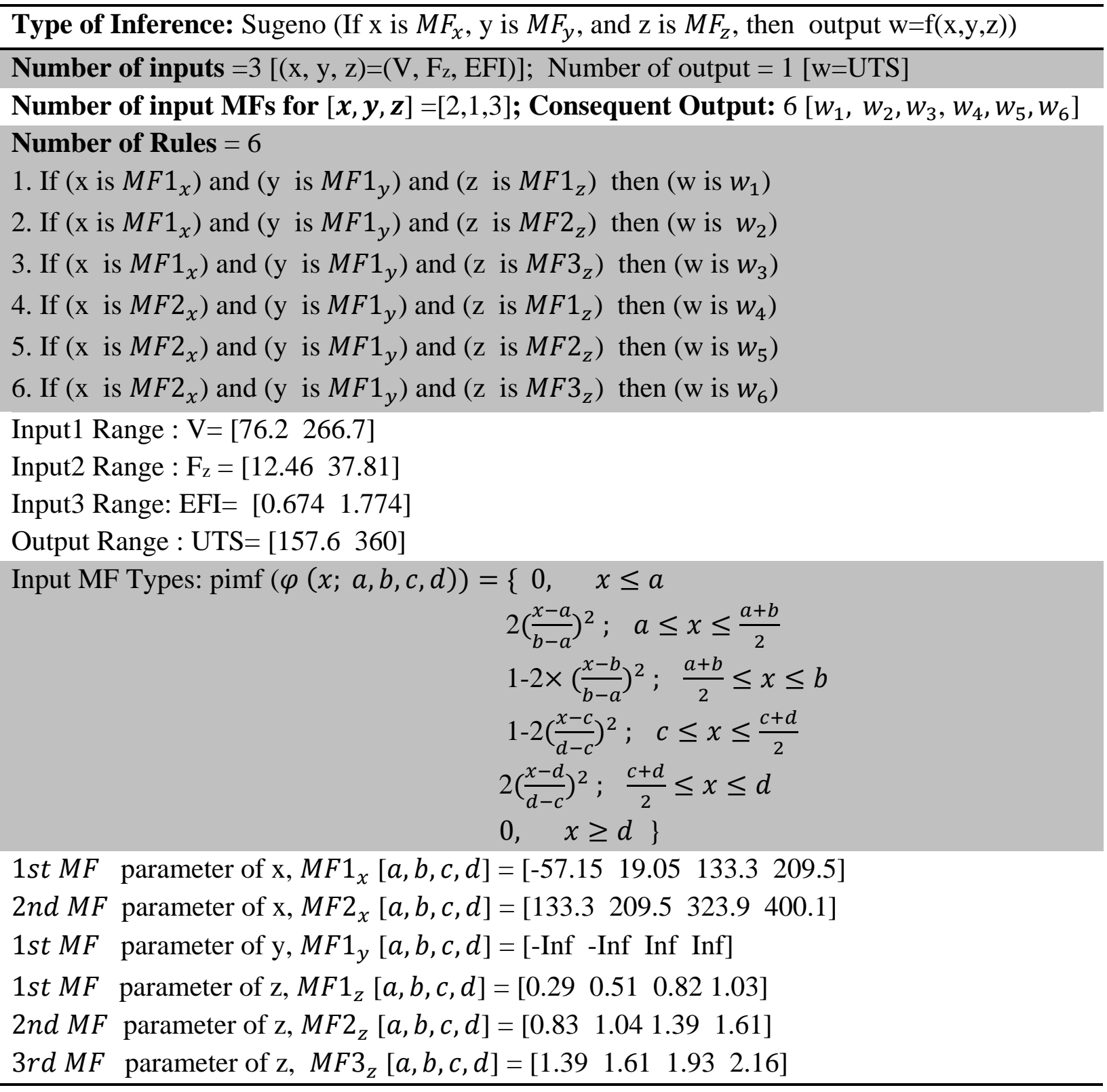




\section{Output parameters: $\mathrm{w}=f(x, y, z)=a_{0}+a_{1} x+a_{2} y+a_{3} z$}

Output parameters of rule 1: $\left[w_{1}: a_{0}, a_{1}, a_{2}, a_{3}\right]=\left[\begin{array}{llll}2.46 & -11.65 & 1293 & -919.2\end{array}\right]$

Output Parameters of rule 2: $\left[w_{2}: a_{0}, a_{1}, a_{2}, a_{3}\right]=\left[\begin{array}{llll}-0.0089 & -0.86 & -49.18 & 395.41\end{array}\right]$

Output parameters of rule $3:\left[w_{3}: a_{0}, a_{1}, a_{2}, a_{3}\right]=\left[\begin{array}{lllll}6.39 & -20.59 & -1.079 & 0.041\end{array}\right]$

Output parameters of rule 4: $\left[w_{4}: a_{0}, a_{1}, a_{2}, a_{3}\right]=\left[\begin{array}{llll}1.05 & -9.21 & 661.8 & -252\end{array}\right]$

Output parameters of rule $5:\left[w_{5}: a_{0}, a_{1}, a_{2}, a_{3}\right]=\left[\begin{array}{llll}0.22 & 1.25 & 9.61 & 243.9\end{array}\right]$

Output parameters of rule 6: $\left[w_{6}: a_{0}, a_{1}, a_{2}, a_{3}\right]=\left[\begin{array}{llll}0.91 & -2.93 & -0.15 & 0.0059\end{array}\right]$

Lastly, ANFIS predicted UTS values are plotted in Figure 14 for the model generated utilizing two input variables (V and EFI). For a particular weld speed (V), a range of empirical force indexes (EFI) exist where higher UTS values can be obtained. The Surface plot is helpful to visualize required welding process parameters to achieve certain tensile strength values.

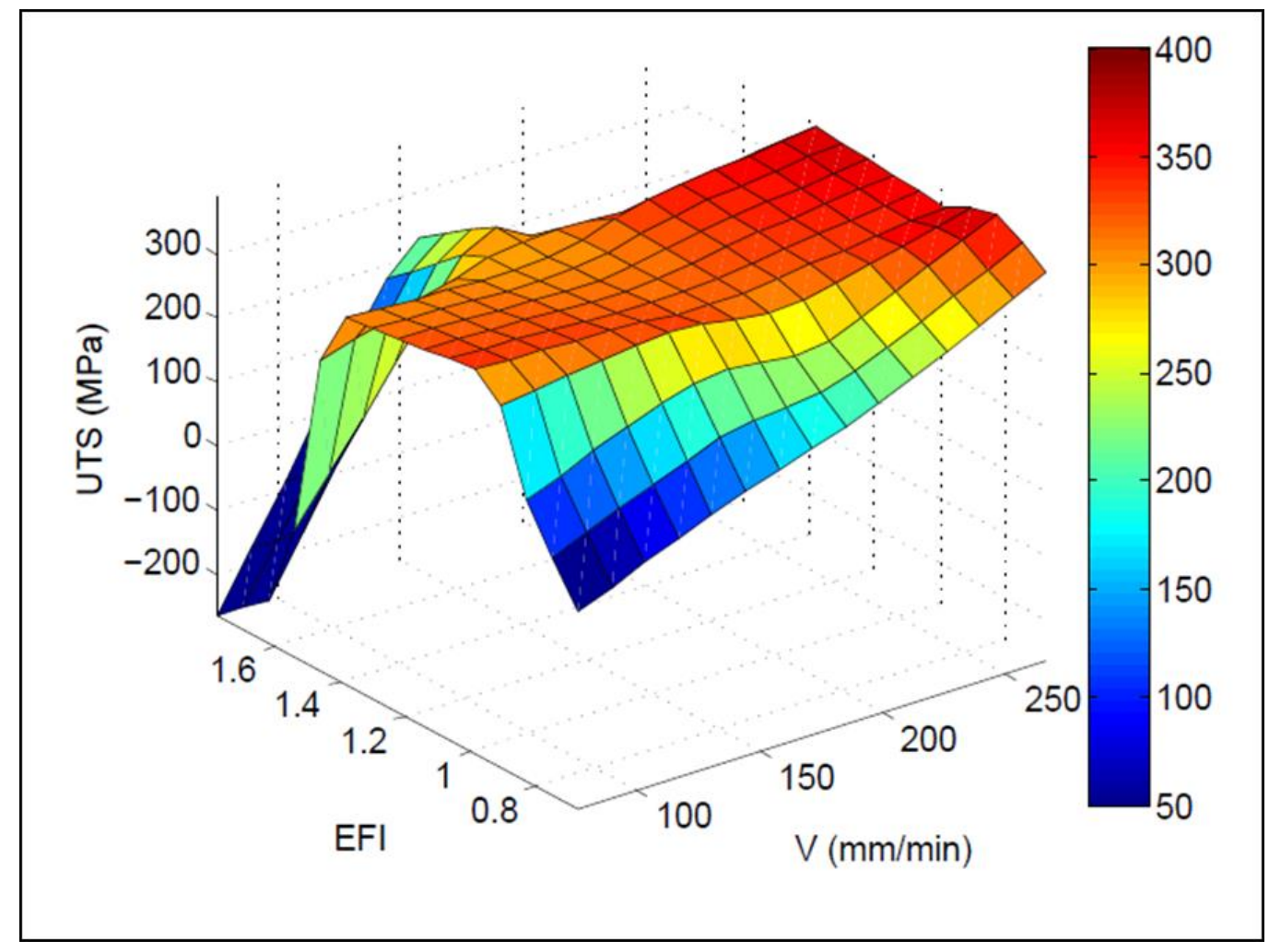

Figure 14: Surface plot showing ANFIS predicted ultimate tensile strength (UTS). Model generated utilizing weld speed $(V)$ and empirical force index (EFI) as input variables

\section{ANN Modeling and Validation}


In ANN model construction, a preliminary analysis was carried out by using all 4 input variables $\left(N, V, F_{z}, E F I\right)$ and dividing the 73 data sets into training (43 data), testing (15 data), and validation (15 data) sets. Before partitioning, the data was randomized. For the same data set and same ANN structure (4-10-1), different runs resulted in different results. To avoid the variation, the LOO-CV approach was utilized to build ANN models, similar to building ANFIS models. Efforts were made to find the best model to ensure fair comparison. Initially, all 4 data input variables $\left(N, V, F_{z}, E F I\right)$ were utilized along with different network training functions (i.e. Levenberg-Marquardt back propagation, quasi-Newton back propagation, and gradient descent with adaptive back propagation) in a MATLAB (R2012a) platform to obtain lowest RMSE and MAPE. It was found that Levenberg-Marquardt back propagation network training function produced best performance.

Thereafter, different combinations of input variables were utilized with single hidden layer and 10 nodes in hidden layer. For each case, the program was repeated 6 times and average RMSE and MAPE values calculated (Table 6). Similar to ANFIS model, the ANN model based on the following three input variables $\left(V, F_{z}\right.$, and $\left.E F I\right)$ produced lowest RMSE (38.28 MPa) and MAPE $(10.64 \%)$ values. For further optimization, the number of nodes in the hidden layer was varied from 3 to 15 to obtain the best model with three input variables $\left(V, F_{z}\right.$, and $\left.E F I\right)$. For each case, the program was run 6 times to obtain average RMSE and MAPE values. It was found that 5 nodes in the hidden layer resulted in best performance $(\mathrm{RMSE}=36.70 \mathrm{MPa}, \mathrm{MAPE}=10.09 \%)$. The basic details of the best ANN model is listed in Table 7. 
Table 6: RMSE and MAPE values for different combination of input variables (Number of hidden layer=1; Number of nodes in hidden layer $=10$; Training function= Levenberg-Marquardt back propagation)

\begin{tabular}{cccccc}
\hline & \multicolumn{2}{c}{ Input Parameters } & & RMSE & MAPE \\
\hline $\mathbf{N}$ & $\mathrm{V}$ & Fz & EFI & $(\mathrm{MPa})$ & $(\%)$ \\
$\checkmark$ & $\checkmark$ & $\checkmark$ & $\checkmark$ & 41.03 & 12.38 \\
& $\checkmark$ & $\checkmark$ & $\checkmark$ & $\mathbf{3 8 . 2 8}$ & $\mathbf{1 0 . 6 4}$ \\
$\checkmark$ & $\checkmark$ & $\checkmark$ & & 46.36 & 12.9 \\
$\checkmark$ & $\checkmark$ & & $\checkmark$ & 42.27 & 11.61 \\
$\checkmark$ & & $\checkmark$ & $\checkmark$ & 38.87 & 10.85 \\
$\checkmark$ & $\checkmark$ & & & 61.79 & 17.39 \\
$\checkmark$ & & $\checkmark$ & $\checkmark$ & 52.52 & 15.18 \\
$\checkmark$ & & & $\checkmark$ & 45.62 & 12.59 \\
& $\checkmark$ & $\checkmark$ & & 56.85 & 16.05 \\
& $\checkmark$ & & $\checkmark$ & 43.5 & 11.57 \\
& & $\checkmark$ & $\checkmark$ & 43.31 & 11.95 \\
& & & $\checkmark$ & 49.68 & 13 \\
& & $\checkmark$ & & 68.71 & 19.14 \\
& $\checkmark$ & & & 57.14 & 16.46 \\
$\mathbb{\checkmark}$ & & & & 53.35 & 15.66 \\
\hline
\end{tabular}

Table 7: Basic details of the ANN model with lowest RMSE and MAPE

\begin{tabular}{lc}
\hline \multicolumn{1}{c}{ ANN Model } \\
\hline Network Configuration \\
Number of input nodes & $3(\mathrm{~V}, 5-1, \mathrm{~F}, \mathrm{EFI})$ \\
Number of output nodes & 1 (UTS) \\
Number of hidden layer & 1 \\
Number of hidden nodes & 10 \\
Number of epoch & 100 \\
Learning factor $(\mathrm{Mu})$ & 0.001 \\
Training function & Levenberg-Marquardt back propagation \\
\hline
\end{tabular}

\section{Conclusions}

In the current investigation, an ANFIS model has been developed utilizing weld process parameters to predict UTS of FS welded aluminum alloy joints. The optimization process involves 
testing different combinations of four input variables (rotational speed, welding speed, plunge force, and empirical force index) and varying ANFIS parameters to obtain a model with minimum error (RMSE and MAPE). For comparison, the artificial neural network (ANN) approach was also utilized to develop a model with a similar experimental data set.

The conclusions are:

- For the small experimental data set (73 data points), the leave-one-out cross-validation (LOO-CV) approach was utilized for both ANFIS and ANN model generation and testing. Using the LOO-CV approach, every experimental data point was cross validated and biasness aroused in dividing training and testing data was avoided. LOO-CV also allowed determination of a predicted UTS value for every experimental data point for calculating mean absolute percentage error (MAPE).

- To develop ANFIS and ANN models, four input variables $\left(N, V, F_{z}\right.$, and $\left.E F I\right)$ were utilized and optimized. Among the four input variables, EFI was observed to have strong correlation with UTS compared to other parameters. EFI was formulated from an experimental investigation and found to be non-linearly correlated with the three critical process parameters $\left(N, V, F_{z}\right)$.

- A total of 1200 different ANFIS models were developed by varying number of membership functions (MFs), type of membership function, and combination of four input variables $\left(N, V, F_{z}, E F I\right)$. It was found that the ANFIS model with three input variables $\left(V, F_{z}\right.$, and $\left.E F I\right)$ resulted in lowest RMSE and MAPE values of $29.7 \mathrm{MPa}$ and $7.7 \%$ respectively. 
- The ANN model with three input variables $\left(V, F_{z}\right.$, and $\left.E F I\right)$ resulted in minimum RMSE (36.7 MPa) and MAPE (10.09\%); however, prediction error of the best ANN model is larger than those of the optimized ANFIS model.

- The developed best ANFIS model can be applied to select weld process parameters to achieve desirable joint strength and incorporated into an optimization model for further optimization studies.

The same fixed pin is used throughout this study. In the future, the effect of pin tool design will be incorporated in the model to make the model more powerful. To this end, far more data is needed.

\section{Acknowledgements}

The authors gratefully acknowledge the funding received from NASA through the NASASLS Grant \# NNM13AA02G and the opportunity to aid in the research to create technology which works towards betterment of the United States' Space program. The authors would also like to thank the collaborators at the National Center for Advanced Manufacturing (NCAM), NASA's Marshall Space Flight Center, and NASA’s Michoud Assembly Facility.

\section{Appendix}

\section{Abbreviations}

ANFIS

ANN

CW

EFI

FSW

gauss $2 \mathrm{mf}$

gaussmf
Adaptive neuro-fuzzy inference system

Artificial neural network

Cold weld

Empirical force index

Friction stir welding

Gaussian combination membership function

Gaussian membership function 


$\begin{array}{ll}\text { gbellmf } & \text { Generalized bell membership function } \\ \text { GENFIS } & \text { Generate fuzzy inference system } \\ \text { HW } & \text { Hot weld } \\ \text { IP } & \text { Incomplete penetration } \\ \text { LOO-CV } & \text { Leave-one-out cross validation } \\ \text { MAPE } & \text { Mean absolute percentage error } \\ \text { MFs } & \text { Membership functions } \\ \text { NW } & \text { Nominal weld } \\ \text { pimf } & \pi \text {-membership function } \\ \text { RMSE } & \text { Root mean square error } \\ \text { RSM } & \text { Response surface methodology } \\ \text { TR } & \text { Trenching (surface cavity) } \\ \text { trimf } & \text { triangular membership function } \\ \text { TSK } & \text { Takagi-Sugeno-Kang } \\ \text { UF } & \text { Underfill } \\ \text { UTS } & \text { Ultimate tensile strength } \\ \text { WH } & \text { Wormhole (internal cavity) } \\ \text { WN } & \text { Weld nugget }\end{array}$

\section{References}

[1] Mishra RS, Ma ZY. Friction stir welding and processing. Materials Science and Engineering: R: Reports. 2005;50:1-78.

[2] Record JH, Covington JL, Nelson TW, Sorensen CD, Webb BW. To analyze the effects of nine friction stir welding input parameters on measured process outputs, a 16-run fractional factorial experiment was used. Welding Journal. 2007; 86: 97s-103s.

[3] Rajakumar S, Balasubramanian V. Establishing relationships between mechanical properties of aluminium alloys and optimised friction stir welding process parameters. Materials \& Design. 2012;40:17-35.

[4] Rajakumar S, Muralidharan C, Balasubramanian V. Predicting tensile strength, hardness and corrosion rate of friction stir welded AA6061-T6 aluminium alloy joints. Materials \& Design. 2011;32:2878-90. 
[5] Gopalakrishnan S, Murugan N. Prediction of tensile strength of friction stir welded aluminium matrix TiCp particulate reinforced composite. Materials \& Design. 2011;32:462-7.

[6] Rajakumar S, Muralidharan C, Balasubramanian V. Establishing empirical relationships to predict grain size and tensile strength of friction stir welded AA 6061-T6 aluminium alloy joints. Transactions of Nonferrous Metals Society of China. 2010;20:1863-72.

[7] Elangovan K, Balasubramanian V, Babu S. Developing an empirical relationship to predict tensile strength of friction stir welded AA2219 aluminum alloy. Journal of Materials Engineering and Performance. 2008;17:820-30.

[8] Dinaharan I, Murugan N. Optimization of friction stir welding process to maximize tensile strength of AA6061/ZrB2 in-situ composite butt joints. Metals and Materials International. 2012;18:135-42.

[9] Bozkurt Y. The optimization of friction stir welding process parameters to achieve maximum tensile strength in polyethylene sheets. Materials \& Design. 2012;35:440-5.

[10] Bilici MK. Application of Taguchi approach to optimize friction stir spot welding parameters of polypropylene. Materials \& Design. 2012;35:113-9.

[11] Parida B, Pal S. Fuzzy assisted grey Taguchi approach for optimisation of multiple weld quality properties in friction stir welding process. Science and Technology of Welding and Joining. 2015;20:35-41.

[12] Pradeep A, Muthukumaran S. An analysis to optimize the process parameters of friction stir welded low alloy steel plates International Journal of Engineering, Science and Technology. 2013;5(3), 25-35.

[13] Yang S-H, Srinivas J, Mohan S, Lee D-M, Balaji S. Optimization of electric discharge machining using simulated annealing. Journal of Materials Processing Technology. 2009;209:4471-5.

[14] Chen H-C, Lin J-C, Yang Y-K, Tsai C-H. Optimization of wire electrical discharge machining for pure tungsten using a neural network integrated simulated annealing approach. Expert Systems with Applications. 2010;37:7147-53.

[15] Zain AM, Haron H, Sharif S. Optimization of process parameters in the abrasive waterjet machining using integrated SA-GA. Applied Soft Computing. 2011;11:5350-9.

[16] Liao TW, Daftardar S. Model based optimisation of friction stir welding processes. Science and Technology of Welding and Joining. 2009;14:426-35.

[17] Baş D, Boyacı İH. Modeling and optimization I: Usability of response surface methodology. Journal of Food Engineering. 2007;78:836-45.

[18] Okuyucu H, Kurt A, Arcaklioglu E. Artificial neural network application to the friction stir welding of aluminum plates. Materials \& Design. 2007;28:78-84. 
[19] Ghetiya ND, Patel KM. Prediction of tensile strength in friction stir welded aluminium alloy using artificial neural network. Procedia Technology. 2014;14:274-81.

[20] Shojaeefard MH, Behnagh RA, Akbari M, Givi MKB, Farhani F. Modelling and pareto optimization of mechanical properties of friction stir welded AA7075/AA5083 butt joints using neural network and particle swarm algorithm. Materials \& Design. 2013;44:190-8.

[21] Tansel I, Demetgul M, Okuyucu H, Yapici A. Optimizations of friction stir welding of aluminum alloy by using genetically optimized neural network. The International Journal of Advanced Manufacturing Technology. 2010;48:95-101.

[22] Lakshminarayanan AK, Balasubramanian V. Comparison of RSM with ANN in predicting tensile strength of friction stir welded AA7039 aluminium alloy joints. Transactions of Nonferrous Metals Society of China. 2009;19:9-18.

[23] Jayaraman M, Sivasubramanian R, Balasubramanian V, Lakshminarayanan AK. Prediction of tensile strength of friction stir welded A356 cast aluminium alloy using response surface methodology and artificial neural network. Journal for Manufacturing Science and Production. 2008.9: 45-60.

[24] Jang J. ANFIS: adaptive-network-based fuzzy inference system. IEEE Transactions on Systems, Man and Cybernetics. 1993;23:665-85.

[25] Roshan SB, Jooibari MB, Teimouri R, Asgharzadeh-Ahmadi G, Falahati-Naghibi M, Sohrabpoor H. Optimization of friction stir welding process of AA7075 aluminum alloy to achieve desirable mechanical properties using ANFIS models and simulated annealing algorithm. The International Journal of Advanced Manufacturing Technology. 2013;69:1803-18.

[26] Dong M, Wang N. Adaptive network-based fuzzy inference system with leave-one-out cross-validation approach for prediction of surface roughness. Applied Mathematical Modelling. 2011;35:1024-35.

[27] Jalali-Heravi M, Kyani A. Comparison of shuffling-adaptive neuro fuzzy inference system (Shuffling-ANFIS) with conventional ANFIS as feature selection methods for nonlinear systems. QSAR \& Combinatorial Science. 2007;26:1046-59.

[28] Shahbazikhah P, Asadollahi-Baboli M, Khaksar R, Alamdari RF, Zare-Shahabadi V. Predicting partition coefficients of migrants in food simulant/polymer systems using adaptive neuro-fuzzy inference system. Journal of the Brazilian Chemical Society. 2011;22:1446-51.

[29] Tsujitani M, Tanaka Y. Cross-validation, bootstrap, and support vector machines. Advances in Artificial Neural Systems. 2011;2011:1-6.

[30] Andersen K, Cook GE, Karsai G, Ramaswamy K. Artificial neural networks applied to arc welding process modeling and control. IEEE Transactions on Industry Applications. 1990;26:824-30. 
[31] Zhang Z, Friedrich K. Artificial neural networks applied to polymer composites: a review. Composites Science and Technology. 2003;63:2029-44.

[32] Nagesh DS, Datta GL. Prediction of weld bead geometry and penetration in shielded metalarc welding using artificial neural networks. Journal of Materials Processing Technology. 2002;123:303-12.

[33] Takagi T, Sugeno M. Fuzzy identification of systems and its applications to modeling and control. IEEE Transactions on Systems, Man and Cybernetics. 1985;SMC-15:116-32.

[34] Liao TW. Classification of welding flaw types with fuzzy expert systems. Expert Systems with Applications. 2003;25:101-11.

[35] Guillaume S. Designing fuzzy inference systems from data: An interpretability-oriented review. IEEE Transactions on Fuzzy Systems. 2001;9:426-43.

[36] Sheng C, Xia H, Harris CJ, Xunxian W. Identification of nonlinear systems using generalized kernel models. IEEE Transactions on Control Systems Technology. 2005;13:401-11.

[37] AWS. Specification for Friction Stir Welding of Aluminum Alloys for Aerospace Applications. Miami, Florida 33126200X.

[38] Long T, Tang W, Reynolds AP. Process response parameter relationships in aluminium alloy friction stir welds. Science and Technology of Welding and Joining. 2007;12:311-7.

[39] Doude H, Schneider J, Patton B, Stafford S, Waters T, Varner C. Optimizing weld quality of a friction stir welded aluminum alloy. Journal of Materials Processing Technology. 2015;222:188-96.

[40] Arora KS, Pandey S, Schaper M, Kumar R. Microstructure evolution during friction stir welding of aluminum alloy AA2219. Journal of Materials Science \& Technology. 2010;26:747-53.

[41] Colligan K. Relationships between process variables related to heat generation in friction stir welding of aluminum. . In: Mishra RS, Mahoney MW, Lienert TJ, Jata KV, editors. Friction Stir Welding and Processing IV Symposia: John Wiley \& Sons, Inc.; 2007. p. 3954.

[42] Gharacheh MA, Kokabi AH, Daneshi GH, Shalchi B, Sarrafi R. The influence of the ratio of "rotational speed/traverse speed" $(\omega / \mathrm{v})$ on mechanical properties of AZ31 friction stir welds. International Journal of Machine Tools and Manufacture. 2006;46:1983-7. 


\section{List of Figures}

Figure 1: Schematic of artificial neural network (ANN) layers (two input variables, two hidden layers with 3 nodes each, and one output)

Figure 2: Schematic of ANFIS architecture for two inputs and two rules based on the first-order Sugeno model [24]

Figure 3: Photograph of (a) FSW machine and (b) FSW setup showing three critical process parameters $\left(F_{Z}, V, N\right)$ and pin-tool with dimensions

Figure 4: Photograph of tensile test- (a) specimens before test, (b) specimens after test, and (c) setup with extensometer

Figure 5: Typical tensile stress-strain plots of base and FS-welded (nominal, hot, and cold welds) AA2219-T87 specimens

Figure 6: Typical SEM micrographs showing microstructure in weld nugget (WN) of (a) nominal weld (NW), (b) hot weld (HW), and (c) cold weld (CW) joints

Figure 7: Ultimate tensile strength (UTS) and tensile toughness of FSW joint with different weld defects (NW: defect free nominal weld, HW: hot weld with underfill and micro-voids, CW-IP: cold weld with incomplete penetration, CW-WH: cold weld with wormhole, CW-TR: cold weld with trenching)

Figure 8: Effect speed ratio (R) on tensile strength: (a) Speed ratio vs. UTS at constant $F_{z}$, (b) $F_{z}$ vs. UTS at constant speed ratio

Figure 9: Welding process parameter window and correlation among three critical process parameters $\left(\mathrm{N}, \mathrm{V}, \mathrm{F}_{\mathrm{z}}\right)$ for defect free nominal weld schedules

Figure 10: Experimental transverse ultimate tensile strength (UTS) of friction stir welded aluminum alloy joints are plotted against empirical force index (EFI)

Figure 11: Variations of root mean square (RMS) error for different set of training and testing data

Figure 12: Experimental and ANFIS model predicted UTS plotted for best the model developed utilizing three input variables $\left(\mathrm{N}, \mathrm{V}, \mathrm{F}_{\mathrm{z}}\right)$

Figure 13: Experimental and ANFIS model predicted UTS plotted for best the model developed utilizing three input variables $\left(\mathrm{V}, \mathrm{F}_{\mathrm{z}}, \mathrm{EFI}\right)$

Figure 14: Surface plot showing ANFIS predicted ultimate tensile strength (UTS). Model generated utilizing weld speed (V) and empirical force index (EFI) as input variables 


\section{$\underline{\text { List of Tables }}$}

Table 1: Friction stir welding process parameters and ultimate tensile strengths of AA-2219-T87 joints

Table 2: Result from ANFIS model developed utilizing different combinations of three input variables $\left(\mathrm{N}, \mathrm{V}, \mathrm{F}_{\mathrm{z}}\right)$ along with types and numbers of membership functions associated with input variables

Table 3: Result from ANFIS model developed utilizing four input variables $\left(\mathrm{N}, \mathrm{V}, \mathrm{F}_{\mathrm{z}}, \mathrm{EFI}\right)$

Table 4: Comparison between experimental and ANFIS predicted UTS

Table 5: ANFIS parameters for the best model

Table 6: RMSE and MAPE values for different combination of input variables (Number of hidden layer $=1$; Number of nodes in hidden layer $=10$; Training function $=$ LevenbergMarquardt back propagation)

Table 7: Basic details of the ANN model with lowest RMSE and MAPE 